\title{
Ganoderma lucidum Spore Polysaccharide Inhibits the Growth of Hepatocellular Carcinoma Cells by Altering Macrophage Polarity and Induction of Apoptosis
}

\author{
Ming Song $\mathbb{D},{ }^{1}$ Zhen-hao Li, ${ }^{2}$ Hong-shun Gu, ${ }^{3}$ Ru-ying Tang, ${ }^{4}$ Rui Zhang, ${ }^{1}$ Ying-li Zhu, ${ }^{4}$ \\ Jin-lian Liu, ${ }^{1}$ Jian-jun Zhang ${ }^{1},{ }^{1}$ and Lin-yuan Wang $\mathbb{1}^{4}$ \\ ${ }^{1}$ School of Traditional Chinese Medicine, Beijing University of Chinese Medicine, Beijing 100029, China \\ ${ }^{2}$ Zhejiang Shouxiangu Institute of Rare Medicine Plant, Wuyi, 321200, China \\ ${ }^{3}$ Beijing Cairui Medicine Technology Institute, Beijing 100094, China \\ ${ }^{4}$ School of Chinese Materia Medica, Beijing University of Chinese Medicine, Beijing 100029, China
}

Correspondence should be addressed to Jian-jun Zhang; zhangjianjun@bucm.edu.cn and Lin-yuan Wang; wangly@bucm.edu.cn

Received 4 January 2021; Revised 2 February 2021; Accepted 10 February 2021; Published 5 March 2021

Academic Editor: Kai Wang

Copyright (c) 2021 Ming Song et al. This is an open access article distributed under the Creative Commons Attribution License, which permits unrestricted use, distribution, and reproduction in any medium, provided the original work is properly cited.

\begin{abstract}
Background. Ganoderma lucidum has certain components with known pharmacological effects, including strengthening immunity and anti-inflammatory activity. G. lucidum seeds inherit all its biological characteristics. G. lucidum spore polysaccharide (GLSP) is the main active ingredient to enhance these effects. However, its specific biological mechanisms are not exact. Our research is aimed at revealing the specific biological mechanism of GLSP to enhance immunity and inhibit the growth of H22 hepatocellular carcinoma cells. Methods. We extracted primary macrophages (Mø) from BALB/c mice and treated them with GLSP $(800 \mu \mathrm{g} / \mathrm{mL}, 400 \mu \mathrm{g} / \mathrm{mL}$, and $200 \mu \mathrm{g} / \mathrm{mL})$ to observe its effects on macrophage polarization and cytokine secretion. We used GLSP and GLSP-intervened macrophage supernatant to treat H22 tumor cells and observed their effects using MTT and flow cytometry. Moreover, real-time fluorescent quantitative PCR and western blotting were used to observe the effect of GLSPintervened macrophage supernatant on the PI3K/AKT and mitochondrial apoptosis pathways. Results. In this study, GLSP promoted the polarization of primary macrophages to M1 type and the upregulation of some cytokines such as TNF- $\alpha$, IL- $1 \beta$, IL-6, and TGF- $\beta 1$. The MTT assay revealed that GLSP+Mø at $400 \mu \mathrm{g} / \mathrm{mL}$ and $800 \mu \mathrm{g} / \mathrm{mL}$ significantly inhibited H22 cell proliferation in a dose-dependent manner. Flow cytometry analysis revealed that GLSP+Mø induced apoptosis and cell cycle arrest at the G2/M phase, associated with the expression of critical genes and proteins (PI3K, p-AKT, BCL-2, BAX, and caspase9) that regulate the PI3K/AKT pathway and apoptosis. GLSP reshapes the tumor microenvironment by activating macrophages, promotes the polarization of primary macrophages to M1 type, and promotes the secretion of various inflammatory factors and cytokines. Conclusion. Therefore, as a natural nutrient, GLSP is a potential agent in hepatocellular carcinoma cell treatment and induction of apoptosis.
\end{abstract}

\section{Introduction}

Hepatocellular carcinoma (HCC) is the most life-threatening disease worldwide, having high mortality and poor prognosis and an incidence of more than one million cases per year [1]. At present, the treatments for liver cancer are surgery, radiotherapy, and chemotherapy [2]. Its occurrence and development are closely related to various molecular mechanisms in the cell. Recently, an increasing number of chemical drugs and new targeted drugs have been developed. However, some patients are still resistant to drugs. Therefore, the development of new natural medicines is expected to become another strategy for treating liver cancer. Active extracts of various natural medicinal plants have been tested for cancer treatment and have shown good antitumor efficacy [3].

Nowadays, researches have focused on the immunomodulation and antitumor activity of natural products, and this has become the focus of emerging research [4]. 


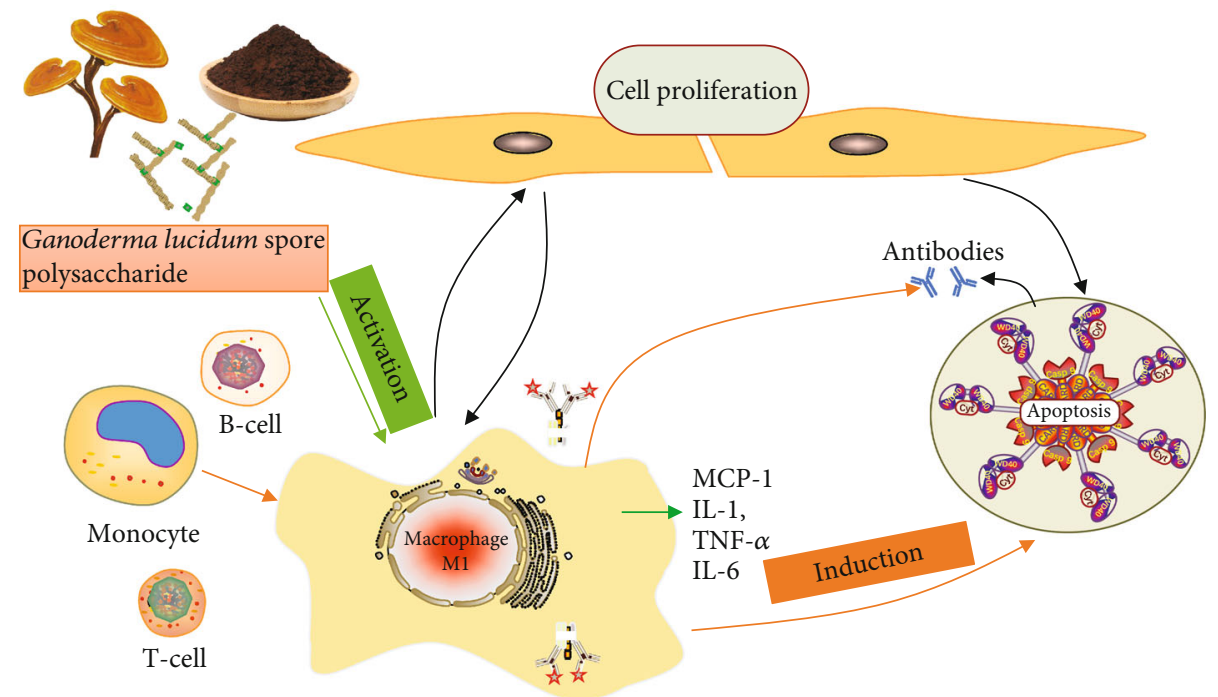

FIGURE 1: GLSP enhances immunity and induces tumor cell apoptosis by activating macrophages. GLSP: Ganoderma lucidum spore polysaccharide.

Naturally sourced antitumor drugs have been shown to exhibit therapeutic effects and few adverse reactions in tumor therapy. They can repair the body's immune system and even cure tumors [5]. Ganoderma lucidum, which is also called "Lingzhi" has been used medicinally for more than 2000 years [6] and has been regarded as an effective medicinal compound, reinforcing healthy qi to restore normal function and prolong life and has almost no toxic side effects [7]. G. lucidum spores are microscopic and are ejected from the cap during growth and maturation. These germ cells have all of G. lucidum genetically active substances [8]. Modern pharmacological studies have shown that G. lucidum spores have antitumor effects, increase immune regulation, lower blood sugar and lipid, increase anti-inflammatory and antihypoxia ability, and scavenge free radicals [9].

Macrophages (Mø) play an essential role in humoral and cellular immunity and in maintaining tissue homeostasis [10]. Related studies have found that macrophages are incredibly plastic and can be activated into a series of continuously adjustable functional states under the stimulation of different environments or drugs [11]. Classically activated (M1 type) macrophages and alternatively activated (M2 type) macrophages are the two extremes of this state. The process by which naive (M $\varphi$ type) macrophages are stimulated by exogenous factors in specific tissues to differentiate into M1 or M2 macrophages is called macrophage polarization [12]. The dynamic balance between M1 and M2 is vital for maintaining homeostasis. Once the balance is broken, the human body faces a variety of diseases that can sometimes be treated with drugs to regulate these macrophages. The transformation of M1 and M2 macrophages is a dynamic and reversible process. Directional polarization may provide new methods for cancer treatment $[13,14]$.

Tumor-associated macrophages (TAMs) are similar to the function of immune cells in the tumor microenvironment and mainly infiltrate the tumor matrix to mediate inflamma- tion [15]. The secretion of cytokines, chemokines, growth factors, and proteases and the regulation of intracellular signaling pathways play a vital role in modulating the function of TAMs and tumor cells. The tumor microenvironment combines chronic inflammation, low oxygen levels, nutritional deficiencies, and acidosis, creating extremely complex dynamic systems [16] that regulate tumor growth, proliferation, metastasis, and immune escape. Therefore, we think that the treatment of tumors by reducing the stress state of the tumor's internal environment and then feeding it back to the tumor cells may promote tumor cell apoptosis or autophagy $[17,18]$. Supernatant transfer of various cell cocultures in vitro has been used to mimic the tumor microenvironment [19].

By comparing the content and composition of GLSP and G. lucidum polysaccharides (GLP), we found that the overall structure is similar, but there are still many differences. At present, more than 200 kinds of substances have been separated, of which the largest is $\beta$-glucan and a few are $\alpha$-glucan [20]. Although there have been many studies on GLP, because the shell of G. lucidum spores is hard and difficult to remove completely, we apply a brand-new removal wall technology that makes it possible to extract GLSP with higher purity. GLSP has better physical and chemical properties than GLP, and its application prospects are broader [21, 22]. Besides, GLSP plays a vital role in nourishing and protecting the liver, resisting radiation, resisting gene mutations, and resisting inflammation. Such effects have not been confirmed in GLP-related studies.

In our previous experiments, we found that the G. lucidum spore water extract had no inhibitory effect on $\mathrm{H} 22$ liver cancer cells and no cytotoxicity. However, when added to macrophages, it had a significant inhibitory effect on $\mathrm{H} 22$ liver tumor cells. To clarify the antitumor mechanism of $G$. lucidum spores, we studied the antitumor activity of G. luci$d u m$ spore polysaccharides (GLSP). We speculate that it is one of the targets of liver cancer, as shown in Figure 1. 

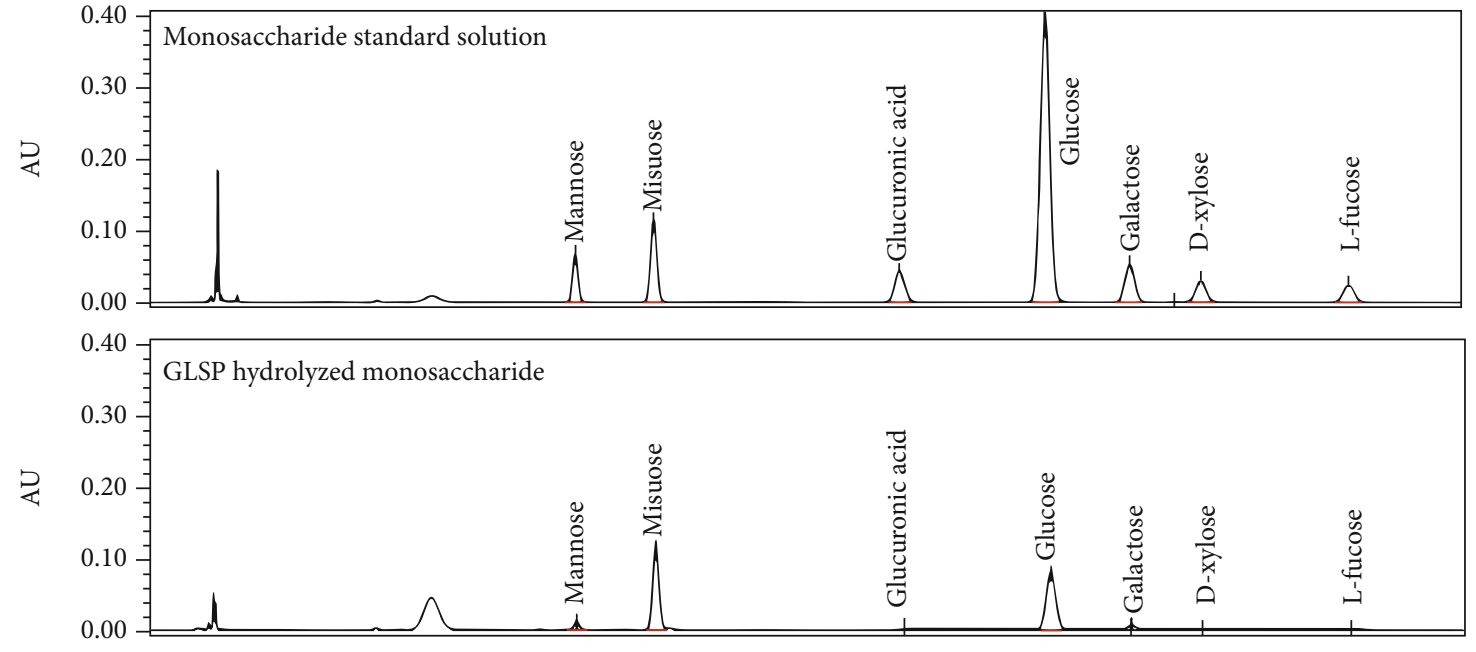

FIGURE 2: HPLC chromatograms of standard monosaccharide solution and GLSP hydrolysate.

\section{Materials and Methods}

2.1. Cells and Animals. Mouse $\mathrm{H} 22$ cells were obtained from Jiangsu KeyGEN BioTECH Co., Ltd. The culture conditions were $90 \%$ RMPI1640 medium $+10 \%$ FBS, cultured in an incubator at $37^{\circ} \mathrm{C}, 5 \% \mathrm{CO}_{2}$, and saturated humidity. Sixteen $\mathrm{BALB} / \mathrm{c}$ mice (male; age range, 4-6 weeks), weighing $20.0 \pm$ $2.0 \mathrm{~g}$, were obtained from the Vital River Laboratory Animal Technology Limited Company (Beijing, China). The laboratory condition is at room temperature $\left(25 \pm 2{ }^{\circ} \mathrm{C}\right)$ and humidity $(65 \pm 5 \%)$. The ethics committee of Beijing University of Chinese Medicine and the China Academy of Chinese Medicine Sciences approved all the experiments (No. 2016-0012).

2.2. Primary Macrophage Extraction. Mice about six weeks old were shaved on a clean bench for disinfection. The animals were euthanized by cervical dislocation, and they were then immersed in $75 \%$ alcohol for $3-5 \mathrm{~s}$ by the tail. The mice were then fixed on the dissection table. After scrubbing the peritoneal wall with $75 \%$ alcohol, $1 \mathrm{~mL}$ precooled PBS was injected into the abdominal cavity with a $5 \mathrm{~mL}$ syringe, and the abdomen was gently massaged for 2-3 min. Under aseptic conditions, the abdominal wall was opened, the peritoneum was exposed, and the abdominal wall was scrubbed with $75 \%$ alcohol. The peritoneal fluid was aspirated with a syringe and centrifuged at $4^{\circ} \mathrm{C}$ at $1000 \mathrm{rpm} / \mathrm{min}$ for $10 \mathrm{~min}$. Finally, 10\% calf serum RPMI-1640 solution was used to suspended cells. Peritoneal macrophages were collected, viable cells $>95 \%$ with trypan blue staining were collected, the cell concentration was adjusted to $5.0 \times 10^{5}$ cells $/ \mathrm{mL}$ with RPMI-1640 medium, and they were inoculated into culture flasks and placed in a $5 \% \mathrm{CO}_{2}, 37^{\circ} \mathrm{C}$ incubator. After 4 hours of culture, the nonadherent cells were washed with PBS to obtain purified peritoneal macrophages.

2.3. Preparation of Ganoderma lucidum Spore Powder. A total of $80 \mathrm{~g}$ of the wall-removed G. lucidum spore powder was extracted with $95 \%$ ethanol in a $5000 \mathrm{~mL}$ round flask. After removing ethanol, the residue was added $2400 \mathrm{~mL}$ of water (30 times the amount of water) and refluxed for $3 \mathrm{~h}$. The solution was then filtered and concentrated to $80 \mathrm{~mL}$. Then, $425 \mathrm{~mL}$ of $95 \%$ ethanol diluted to $80 \%$ ethanol was added while stirring, let stand for $12 \mathrm{~h}$ at $0-4^{\circ} \mathrm{C}$, and filtered. The precipitate was taken and dissolved in water and chloroform with $\mathrm{n}$-butanol $(5: 1)$ mixed solution for extraction according to the Sevag method. Then, the solution was shaken for $15 \mathrm{~min}$, the organic layer was removed, and the extraction was repeated four times, concentrated, and dried to obtain GLSP. The GLSP content was $92.7 \%$ according to the test method of the 2015 edition of the "Pharmaceuticals of the People's Republic of China." HPLC chromatograms of standard monosaccharide solution and GLSP hydrolysate are shown in Figure 2.

2.4. Modeling and Drug Delivery. H22 cells were treated for $24 \mathrm{~h}$ under different conditions: only DMEM (control), GLSP $(800 \mu \mathrm{g} / \mathrm{mL}, 400 \mu \mathrm{g} / \mathrm{mL}$, and $200 \mu \mathrm{g} / \mathrm{mL})$, macrophage supernatant, and GLSP $(800 \mu \mathrm{g} / \mathrm{mL}, 400 \mu \mathrm{g} / \mathrm{mL}$, and $200 \mu \mathrm{g} / \mathrm{mL})$ +macrophage supernatant combination. The concentrations of GLSP $(800 \mu \mathrm{g} / \mathrm{mL}, 400 \mu \mathrm{g} / \mathrm{mL}$, and $200 \mu \mathrm{g} / \mathrm{mL})$ used in this study resulted in no inhibitory activity on macrophage growth. Culture supernatants were collected to measure levels of TNF- $\alpha$, TGF- $\beta 1$, IL- 6 , and IL- $1 \beta$. Each group of cells was subsequently harvested to determine intracellular reactive oxygen species (ROS) production for western blot (WB) analyses and other experiments.

2.5. MTT Assay. H22 cells were digested, counted, and prepared into a cell suspension at a concentration of $5 \times$ $10^{4}$ cells $/ \mathrm{mL}$. The plate was placed at $37^{\circ} \mathrm{C}, 5 \% \mathrm{CO}_{2}$ for $24 \mathrm{~h}$ in a box. The drug was diluted with complete medium to the required concentration $(200 \mu \mathrm{g} / \mathrm{mL}, 400 \mu \mathrm{g} / \mathrm{mL}$, and $800 \mu \mathrm{g} / \mathrm{mL})$. Then, $100 \mu \mathrm{L}$ of the corresponding drugcontaining medium and $100 \mu \mathrm{L}$ of macrophage supernatant were added to each well. After $24 \mathrm{~h}$ of incubation in the box, $20 \mu \mathrm{L}$ MTT ( $5 \mathrm{mg} / \mathrm{mL}$ ) (Amresco, Solon, Ohio, USA) was added and continued to incubate for $4 \mathrm{~h}$ in the incubator. $150 \mu \mathrm{L}$ DMSO was added to dissolve the MTT and shaken 
gently for 10 mins. Absorbance was then measured at $\lambda=490$ $\mathrm{nm}$; the optical density (O.D.) was determined to calculate the inhibition rate. Inhibitory rate $(\%)=[(C-T) / C] \times 100$, where $C$ is the control group and $T$ is that of the treatment group.

2.6. Cell Cycle Analysis. $\mathrm{H} 22$ cells were treated with macrophages and different concentrations of GLSP $(200 \mu \mathrm{g} / \mathrm{mL}$, $400 \mu \mathrm{g} / \mathrm{mL}$, and $800 \mu \mathrm{g} / \mathrm{mL}$ ) for $24 \mathrm{~h}$, collected by digestion, and made into cell suspensions. The cells were washed twice with PBS (centrifuged at $1000 \mathrm{rpm}, 5 \mathrm{~min}$ ). The prepared single-cell suspension was stored at $4^{\circ} \mathrm{C}$ and washed with PBS before staining the fixing solution. Next, $100 \mu \mathrm{L}$ RNaseA was added to a $37^{\circ} \mathrm{C}$ water bath for $30 \mathrm{~min}$ and added $400 \mu \mathrm{L}$ propidium iodide (PI) staining and mixed well. Then, it was incubated at $4^{\circ} \mathrm{C}$ for $30 \mathrm{~min}$. Flow cytometry analysis (Becton-Dickinson FACSCalibur; Becton-Dickinson, USA) detected the fluorescence of the PI-DNA complex and at $488 \mathrm{~nm}$ red fluorescence.

2.7. Annexin V-FITC/PI Double Staining Assay. H22 cells were treated with macrophages and GLSP for $24 \mathrm{~h}$, and the cells were collected. Cells were washed twice with PBS. Then, $500 \mu \mathrm{L}$ of Binding Buffer was added to suspend the cells, $5 \mu \mathrm{L}$ of Annexin V-FITC was added and mixed well, and $5 \mu \mathrm{L}$ of PI was added and mixed with $5 \mu \mathrm{L}$ propidium iodide (PI) using an Annexin V-FITC/PI staining kit (KeyGEN BioTECH), Cat number: KGA105-KGA108. This was incubated for $15 \mathrm{~min}$ in the dark. Flow cytometry analysis was used to detect cell apoptosis.

2.8. Intracellular Reactive Oxygen Species (ROS) Analysis. Cellular ROS were detected using a ROS Assay Kit (KeyGEN BioTECH Co., Ltd., Nanjing, China), Cat number: KGT0101. DCFH-DA was diluted with serum-free culture medium at $1: 1000$ to a final concentration of $10 \mu \mathrm{M}$. After the cells were collected, they were suspended in the diluted DCFH-DA and incubated at $37^{\circ} \mathrm{C}$ for $20 \mathrm{~min}$. The cells were mixed by inversion every 3-5 min. Cells were washed with serum-free cell culture medium three times to remove the DCFH-DA that had not entered the cells. ROS were analyzed using flow cytometry. Data processing was performed using Cell Quest.

2.9. Mitochondrial Membrane Potential (MMP) Analysis. Mitochondrial membrane potential (MMP) was detected using a JC-1 Apoptosis Detection Kit (KeyGEN BioTECH Co., Ltd., Nanjing, China), Cat number: KGA601-KGA604. H22 cells were treated with macrophages and GLSP for $24 \mathrm{~h}$, before cell collection. $100 \mu \mathrm{L} 10 \mathrm{x}$ incubation buffer was diluted with $900 \mu \mathrm{L}$ sterile deionized water to make $1 \mathrm{x}$ incubation buffer. The incubation buffer was mixed and preheated to $37^{\circ} \mathrm{C} .1 \mu \mathrm{L} \mathrm{JC}-1$ was added to $500 \mu \mathrm{L} 1 \mathrm{x}$ incubation buffer, vortexed, and mixed to prepare JC-1 working solution. A total of $500 \mu \mathrm{L} \mathrm{JC-1}$ working solution was used to suspend the cells uniformly and incubated for 15-20 min in an incubator at $37^{\circ} \mathrm{C}$ and $5 \% \mathrm{CO}_{2}$. Washing was made twice with $1 \mathrm{x}$ incubation buffer, and $500 \mu \mathrm{L}$ of $1 \mathrm{x}$ incubation buffer was used to resuspend the cells.
TAble 1: Primer sequences used in the RT-qPCR analysis.

\begin{tabular}{lcc}
\hline Gene & & Sequences $\left(5^{\prime}-3^{\prime}\right)$ \\
\hline \multirow{2}{*}{ PI3K } & Forward & AGGGAAGCGAGACGGCACTTT \\
& Reverse & CCACTACGGAGCAGGCATAGCA \\
AKT & Forward & CCAAGCACCGTGTGACCATGAA \\
& Reverse & TGGCGACGATGACCTCCTTCTT \\
BAX & Forward & CCAGGATGCGTCCACCAAGAAG \\
& Reverse & CCGTGTCCACGTCAGCAATCAT \\
BCL-2 & Forward & TGCCACCTGTGGTCCATCTGA \\
& Reverse & CTCTGCGAAGTCACGACGGTAG \\
Caspase-9 & Forward & GCCACTGCCTCATCATCAACAA \\
& Reverse & AGCGGAATCGGTGCTCAAGTT \\
\hline
\end{tabular}

2.10. Macrophage Cell Phenotype Detection. Macrophages were inoculated during the logarithmic growth phase into a six-well plate. After the drug was incubated for $24 \mathrm{~h}$, the cells were collected and washed twice with PBS to collect $5 \times 10^{5}$ cells. Then, the supernatant was removed by centrifugation, and $90 \mu \mathrm{L}$ PBS was added to resuspend the cells. The appropriate amounts of antibodies CD86 (BioLegend 105007) and CD206 (BioLegend 141703) were added. The cells were then incubated for $30 \mathrm{~min}$ at $37^{\circ} \mathrm{C}, 400 \mu \mathrm{L}$ PBS was added, and the cell phenotype was detected by flow cytometry.

2.11. Enzyme-Linked Immunosorbent Assay (ELISA) Analysis. Cytokine levels were determined using a commercial ELISA kit (Proteintech, Rosemont, IL, USA). First, all samples, reagents, and working standards were prepared as instructed by the manufacturer. The required number of microplate strips was removed, and the microwells were placed in the strip holder. Then, $100 \mu \mathrm{L}$ of each standard and sample was added to the appropriate wells. A cover seal was pressed firmly onto the top of the microwells. The plate was incubated for $90 \mathrm{~min}$ at $37^{\circ} \mathrm{C}$ in a humid environment. Then, the sealing mold was removed, $100 \mu \mathrm{L}$ was added to each well, and antibody diluent was used to dilute at $1: 30$, except for blanks. And the plates were incubated at $37^{\circ} \mathrm{C}$ for $1 \mathrm{~h} .100 \mu \mathrm{L}$ of TMB was added to each well, shaken gently, and color developed at $37^{\circ} \mathrm{C}$ for 15 minutes. $50 \mu \mathrm{L}$ stop solution was added to each hole. Sample absorbance was read at $450 \mathrm{~nm}$ using a Multiskan ${ }^{\mathrm{TM}}$ GO (Thermo Fisher Scientific, Waltham, MA, USA) detector system.

2.12. Quantitative Real-Time PCR (RT-qPCR). We continued to explore changes in PI3K, AKT, BAX, BCL-2, and caspase9 mRNAs. Total RNA from each sample was extracted using a TRIzol reagent (Thermo Fisher Scientific, Waltham, MA, USA). Then, the determination of RNA concentration and purity and synthesis of cDNA first strand was carried out with $20 \mu \mathrm{L}$ system, using a RevertAid First Strand cDNA Synthesis Kit (Thermo Fisher Scientific). The sequences for primers listed in Table 1 were designed by Primer6 and then synthesized by a biotechnology company (Sangon Biotech Co., Ltd., Shanghai, China). The SYBR ${ }^{\circledR}$ Green PCR Master Mix (Thermo Fisher Scientific) was used to amplify cDNA in the Multicolor Real-time PCR Detection System (Bio- 


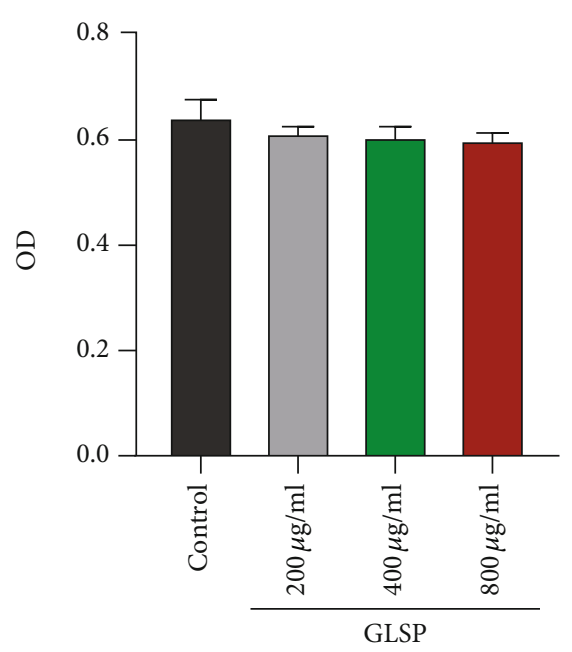

(a)

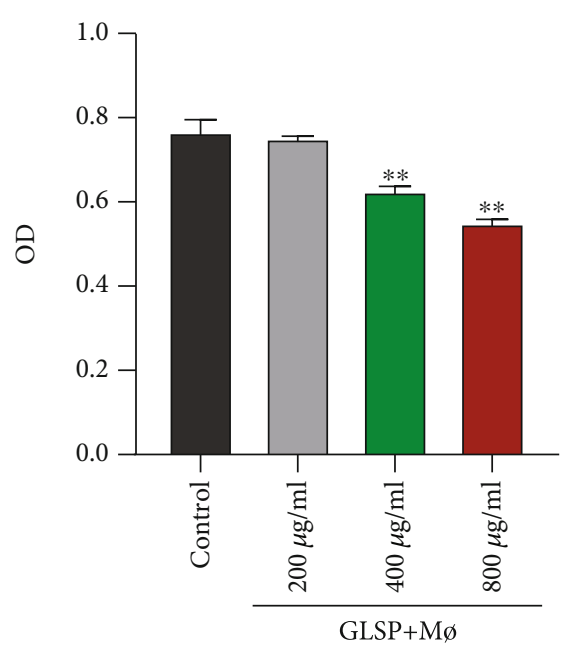

(b)

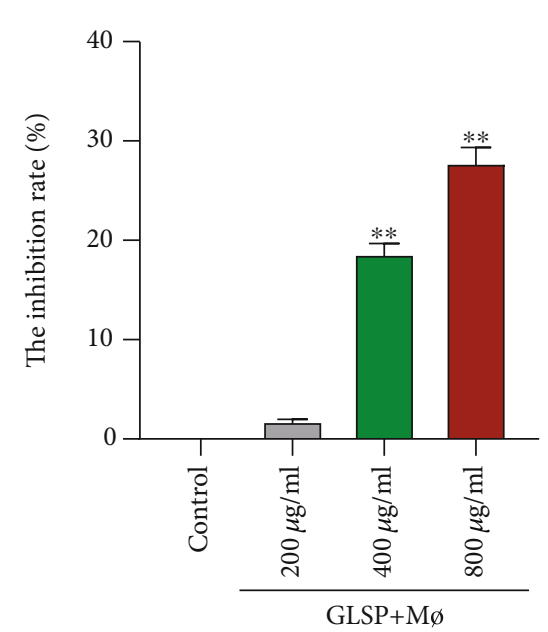

(c)

Figure 3: Inhibitory effects of GLSP and GLSP+Mø on the proliferation of H22 cells. (a) MTT assay reveals no effect on the viability of H22 cells treated with GLSP for $24 \mathrm{~h}$; (b) MTT assay reveals a decrease in the viability of H22 cells treated with different concentrations of GLSP $+\mathrm{M} \varnothing$ for $24 \mathrm{~h},{ }^{* *} \mathrm{P}<0.01$ vs. control group $(24 \mathrm{~h})$; (c) the inhibition rate increases in H22 cells treated with different concentrations of GLSP $+\mathrm{M} ø .{ }^{* *} \mathrm{P}<0.01$ vs. H22 cell control group. GLSP: Ganoderma lucidum spore polysaccharide; OD: optical density.

Rad Laboratories Inc.). The PCR parameters were as follows: $95^{\circ} \mathrm{C}$ for $5 \mathrm{~min}$, followed by 40 cycles of $95^{\circ} \mathrm{C}$ for $15 \mathrm{~s}$ and $72^{\circ} \mathrm{C}$ for $40 \mathrm{~s}$, followed by $60^{\circ} \mathrm{C}$ for $1 \mathrm{~min}$ and $95^{\circ} \mathrm{C}$ for $15 \mathrm{~s}$. The $2^{-\Delta \Delta \mathrm{Ct}}$ method was used to calculate the results.

2.13. Western Blot Analysis. $\mathrm{H} 22$ cells treated with different intervention reagents, including $800 \mu \mathrm{g} / \mathrm{mL}$ GLSP, macrophage culture supernatant, and macrophage culture supernatant containing $800 \mu \mathrm{g} / \mathrm{mL}$ GLSP, were added to the plates and cultured continuously for $24 \mathrm{~h}$. Then, trypsin without EDTA was used for digestion, followed by centrifugation and RIPA lysis solution (Biomiga, Santiago, CA, USA) addition. In line with the molecular weight of the target protein BAX (21 kDa), BCL-2 (26kDa), CASP-9 (46 kDa), p-AKT $(60 \mathrm{kDa}), \mathrm{PI} 3 \mathrm{~K}(85 \mathrm{kDa})$, and AKT $(56 \mathrm{kDa})$, proteins were transferred onto polypropylene fluoride (PVDF) membranes. Nonfat milk (5\%) was used to dilute the antibody. The antibodies used were anti-BAX (50599-2-Ig, mouse polyclonal, diluted $1: 4,000)$, anti-CASP-9 (10380-1-AP, rabbit polyclonal, diluted 1:1000), anti-PI3K (60225-1-Ig, mouse polyclonal, diluted 1:5000), anti-AKT (60203-2-Ig, mouse polyclonal, diluted 1:2000), and anti-GAPDH (60004-1-lg, mouse monoclonal, diluted 1:5,000). All of the above antibodies were from the Proteintech Group: antiBCL-2 (ab182858, diluted 1:2,000; Abcam Group, Cambridge, MA, USA) and anti-p-AKT (CST 4060s, diluted $1: 2,000$; CST, MA, USA). The Tanon-5200 system (Tanon, Shanghai, China) was used for exposure. The intensity of the target protein band was read using Tanon Gis software (Tanon).

2.14. Statistical Analysis. Dates are presented as the mean \pm standard deviation (SD). The data were analyzed using SPSS 22.0 and one-way analysis of variance (ANOVA), or a nonparametric test was used for data processing based on the normality test. And a least significant differ- ence (LSD) method was adopted for comparisons between groups. $P$ value $<0.05$ was considered a statistically significant difference.

\section{Results}

3.1. Cytotoxic Effect of GLSP and Macrophage Supernatant on H22 Cells. The activity of GLSP-treated H22 cells was detected using an MTT assay. Results showed that the proliferation of H22 cells was not affected by treatment with GLSP (Figure 3(a)). However, H22 cell proliferation was notably inhibited by macrophage supernatant $+400 \mu \mathrm{g} / \mathrm{mL}$ GLSP or $+800 \mu \mathrm{g} / \mathrm{mL}$ GLSP $(P<0.01)$ (Figure $3(\mathrm{~b}))$. The results also showed a dose-dependent increase in the inhibition rate of GLSP $(400 \mu \mathrm{g} / \mathrm{mL}$ and $800 \mu \mathrm{g} / \mathrm{mL})+\mathrm{M} \varnothing$ versus the control group $(P<0.01)$ (Figure $3(\mathrm{c}))$.

3.2. GLSP-Activated Macrophages Induce Cell Cycle Arrest at the G2/M Phase in H22 Cells. We examined the cell cycle distribution after treatment with GLSP and macrophage+GLSP. The percentage of $\mathrm{H} 22$ cells treated with macrophages+GLSP $(800 \mu \mathrm{g} / \mathrm{mL})$ in the $\mathrm{G} 2 / \mathrm{M}$ phase was significantly higher than that in the control group (Figures $4(\mathrm{a})$ and $4(\mathrm{~b}))(P<0.01)$, whereas treatment with GLSP alone did not induce the same effect.

3.3. GLSP-Activated Macrophages Promote the Apoptosis of H22 Cells. Results showed that the percentage of apoptotic H22 cells was significantly increased upon macrophage + GLSP treatment (Figures 5(a) and 5(b)) $(P<0.01)$. These results indicated that GLSP-activated macrophages effectively induced $\mathrm{H} 22$ cell apoptosis.

We also examined GLSP-induced changes in MMP. GLSP-activated macrophage treatment induced the conversion of red fluorescence to green fluorescence, indicating a decrease in MMP (Figure 5(c)) $(P<0.01)$. As ROS generation 

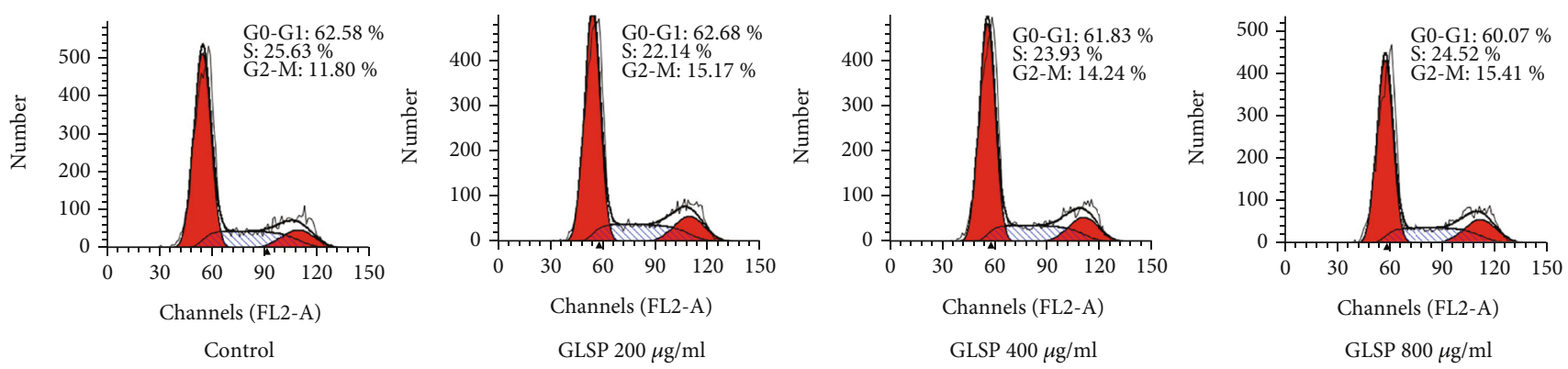

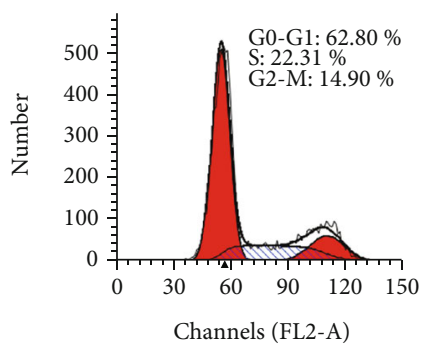

Mø

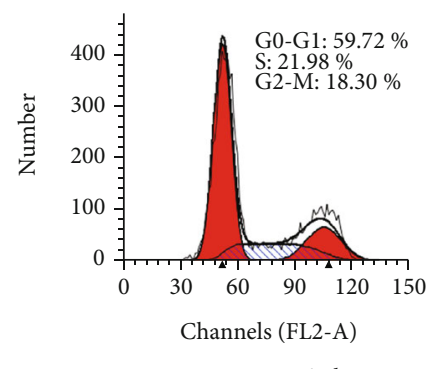

$\mathrm{M} \varnothing+200 \mu \mathrm{g} / \mathrm{ml}$

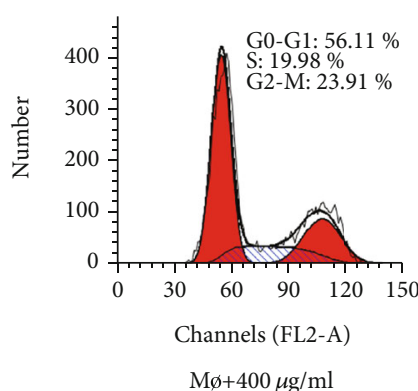

(a)
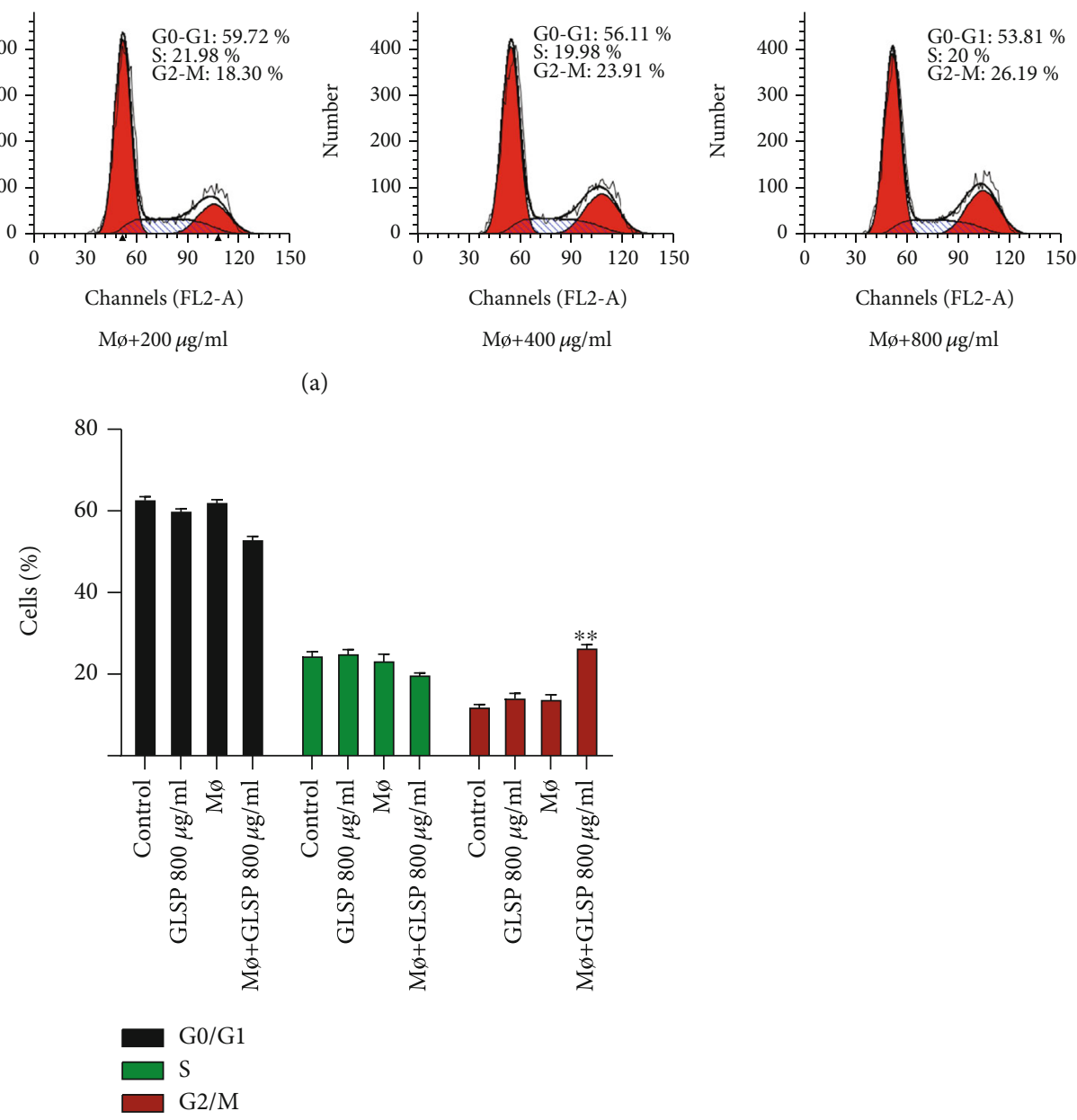

(b)

FIgURE 4: GLSP induces H22 cell arrest at the G2/M phase. (a) Cell cycle distribution of H22 cells treated with GLSP and macrophage supernatant. (b) Percentage in different periods of the cell cycle after GLSP treatment. ${ }^{* *} P<0.01$ vs. H22 cell control group. GLSP: Ganoderma lucidum spore polysaccharide.

is closely related to mitochondrial apoptosis, ROS was detected to test whether oxidative stress had an effect on GLSP-activated macrophage-induced apoptosis in H22 cells. As shown in Figures 5(d) and 5(e), GLSP-activated macrophages led to a significant increase in intracellular ROS levels compared to that of the control group $(P<0.01)$. Therefore, the elevation of ROS production may be a relevant cause of GLSP-activated macrophage-induced apoptosis.

3.4. GLSP Activate Macrophage Polarization. Macrophages are dynamic cells that react to different stimuli by adjusting their functional state. Classically activated macrophages, M1 type, and alternatively activated M2 type are the two extremes of this state. We investigated the polarizing effect of GLSP treatment on macrophages. CD86 analysis revealed that $\mathrm{H} 22$ tumor cells had no effect on macrophage polarization, but GLSP treatment could activate macrophages, which polarized towards M1 type $(P<0.01)$ (Figures 6(a) and 6(b)). CD206 analysis revealed that H22 tumor cells and GLSP independently could increase M2 type macrophages $(P<$ 0.01 ), but $\mathrm{H} 22$ GLSP+macrophages reduced the amount of M2 type (Figures 6(a) and 6(c)). As shown in Figure 5(d), 


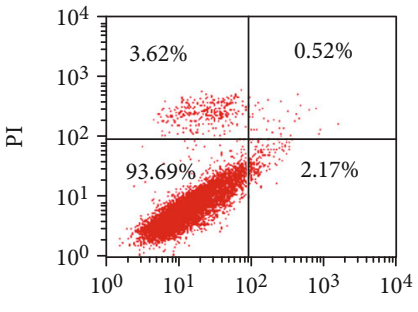

ANNEXIN-V-FITC

Control

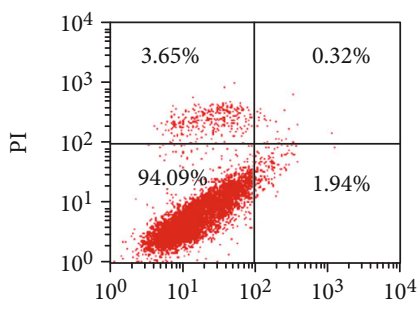

ANNEXIN-V-FITC

Mø

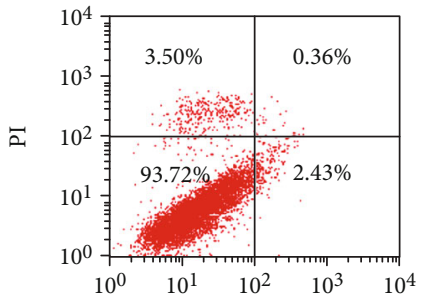

ANNEXIN-V-FITC

GLSP $200 \mu \mathrm{g} / \mathrm{ml}$

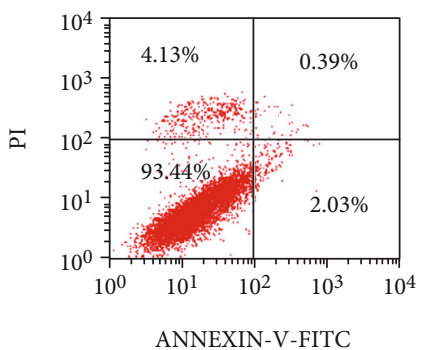

Mø+GLSP $200 \mu \mathrm{g} / \mathrm{ml}$

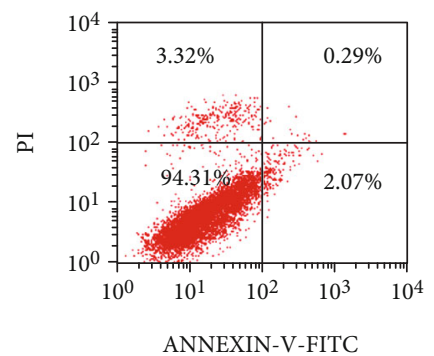

GLSP $400 \mu \mathrm{g} / \mathrm{ml}$

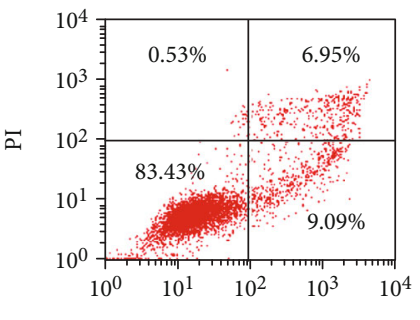

ANNEXIN-V-FITC

Mø+GLSP $400 \mu \mathrm{g} / \mathrm{ml}$

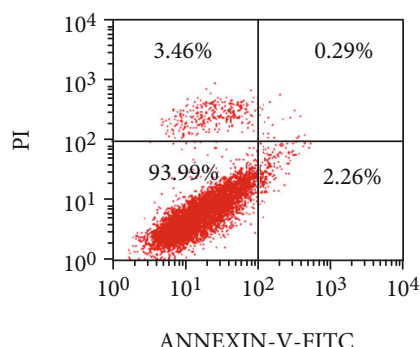

GLSP $800 \mu \mathrm{g} / \mathrm{ml}$

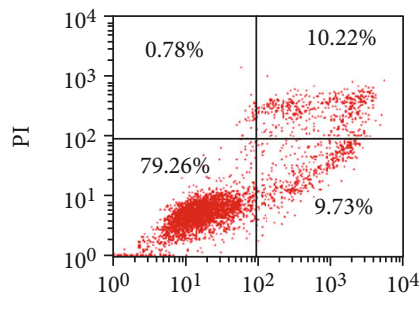

ANNEXIN-V-FITC

(a)

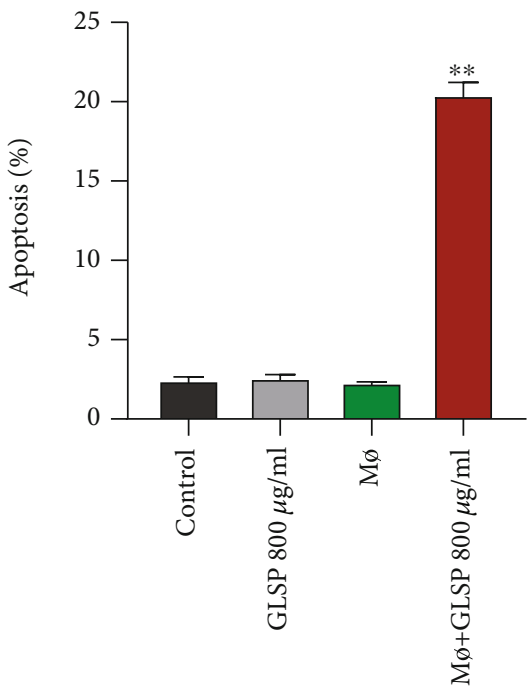

(b)

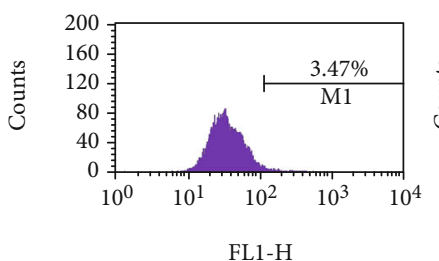

Control

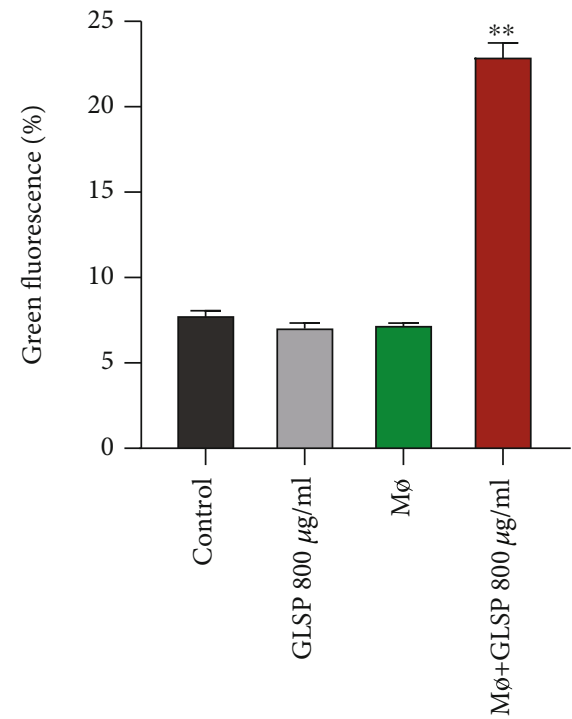

(c)

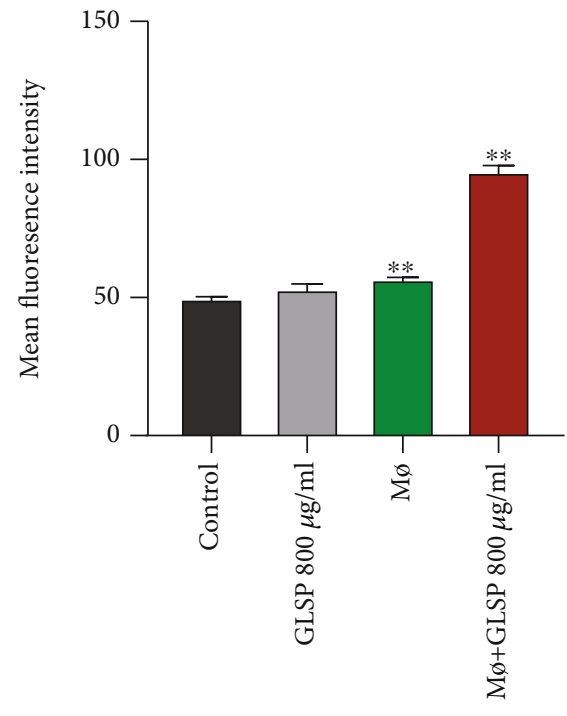

(d)

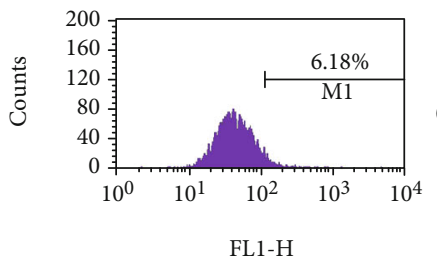

$\mathrm{M} \varnothing$

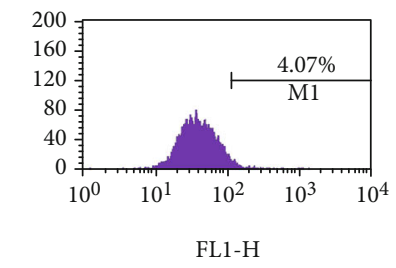

GLSP $800 \mu \mathrm{g} / \mathrm{ml}$

(e)

FIGURE 5: GLSP-activated macrophages induce H22 cell apoptosis. (a) Flow cytometric apoptosis in each group. (b) Percentages of apoptotic cells in each group. (c) FACS assessed MMP based on fluorescent mitochondria. (d) Analyses of ROS levels in H22 cells upon different concentrations of GLSP treatment. (e) Production of intracellular ROS in H22 detected by flow cytometry. Mean Cell Quest Pro analyzed fluorescence intensity. ${ }^{*} P<0.01$ vs. the control group. GLSP: Ganoderma lucidum spore polysaccharide; ROS: reactive oxygen species. 


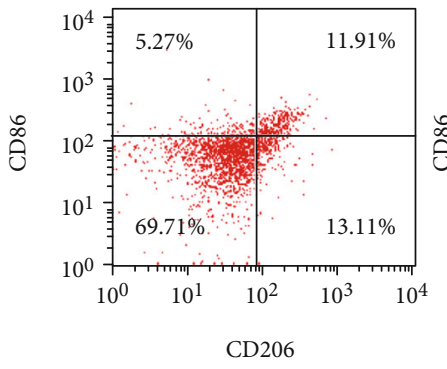

$\mathrm{M \emptyset}$

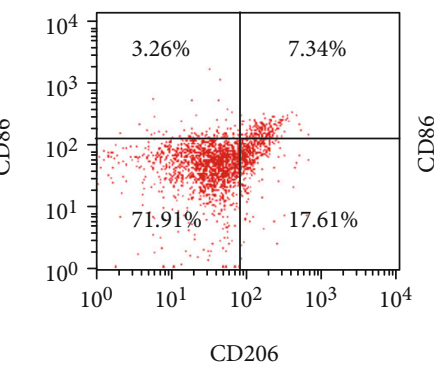

$\mathrm{M} \emptyset+\mathrm{H} 22$

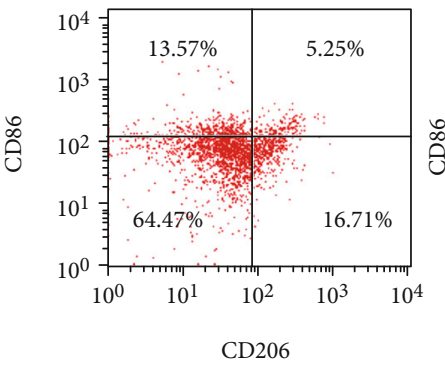

Mø+GLSP $800 \mu \mathrm{g} / \mathrm{ml}$

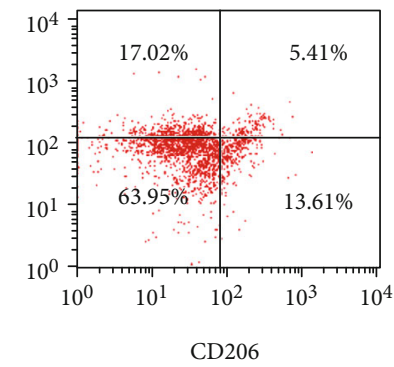

$\mathrm{M} \varnothing+\mathrm{GLSP} 800 \mu \mathrm{g} / \mathrm{ml}+\mathrm{H} 22$

(a)

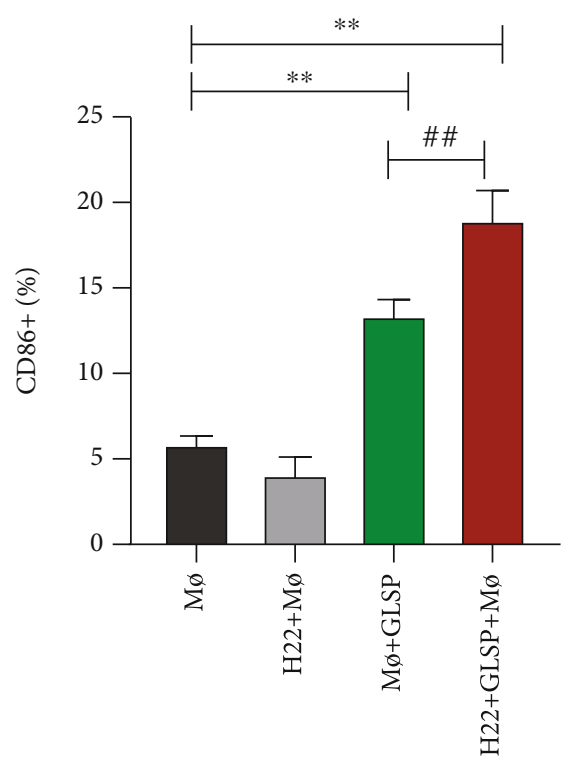

(b)

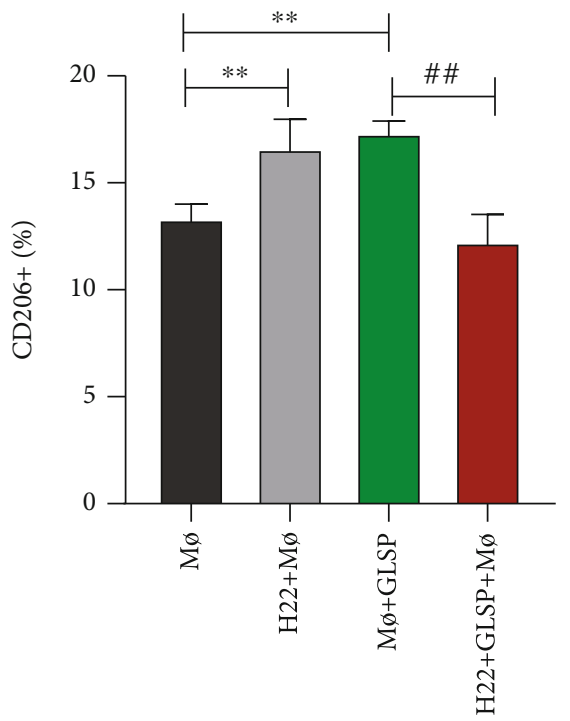

(c)

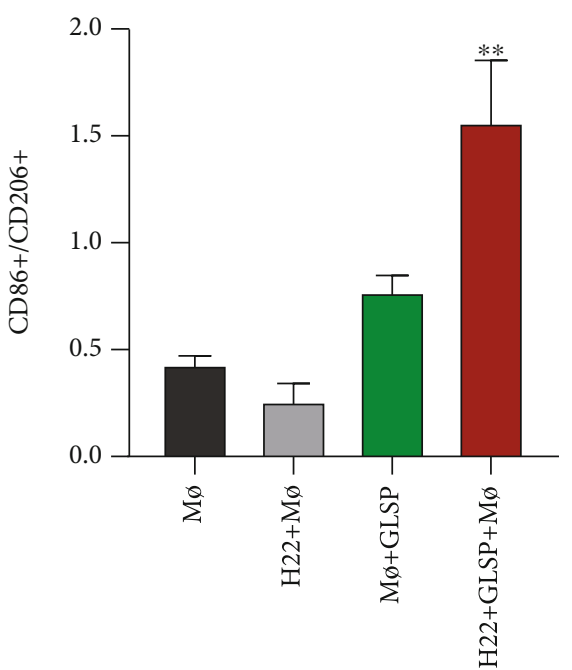

(d)

FIGURE 6: Effect of GLSP on the expression of M1 and M2 macrophage markers: (a) triple staining of flow cytometry analysis of macrophage cells; (b) CD86+ macrophage cells; (c) CD206+ macrophage cells; (d) CD86+/CD206+ macrophage cells. ${ }^{* *} P<0.01$ vs. the control group, ${ }^{\#} P<0.01$ vs. the Mø+GLSP group. GLSP: Ganoderma lucidum spore polysaccharide.

$\mathrm{H} 22+$ macrophages+GLSP improved the ratio of $\mathrm{M} 1 / \mathrm{M} 2$. Therefore, GLSP increases the expression of M1 type macrophages and decreases the expression of M2 type macrophages. The cocultivation group improved the ratio of M1/M2, which affects the polarization of macrophages.

3.5. Effect of GLSP on Cytokine Production. As shown in Figure 7, the TNF- $\alpha$ (Figure 7(a)), IL-1 $\beta$ (Figure 7(b)), IL-6 (Figure $7(\mathrm{c})$ ), and TGF- $\beta 1$ (Figure $7(\mathrm{~d})$ ) levels were significantly higher in the macrophage+GLSP group than in the control group $(P<0.01)$ and in the $\mathrm{H} 22+$ macrophage+GLSP group than in the $\mathrm{H} 22+$ macrophage group $(P<0.01)$.

3.6. GLSP Activate Macrophages Affecting the PI3K/AKT and Mitochondria-Mediated Apoptotic Signaling Pathways. In the above experiments, GLSP activate macrophages effectively, thereby inducing apoptosis and other changes in $\mathrm{H} 22$ cells. Thus, we used RT-qPCR and western blot to explore the differences in apoptotic cell molecules and the PI3K/AKT signaling pathway. At the genetic level, the levels of PI3K were significantly decreased in GLSP+macrophage-treated $\mathrm{H} 22$ cells compared with the control group $(P<0.01)$
(Figure 8(a)). In Figure 8(b), the levels of AKT were not affected in GLSP+macrophage-treated H22 cells versus the control group. We measured the levels of BAX, BCL-2, and CASP-9. The levels of proapoptotic BAX were markedly increased, and antiapoptotic BCL-2 was significantly decreased in GLSP+macrophage-treated H22 cells versus the control group $(P<0.01)$ (Figures $8(\mathrm{c})$ and $8(\mathrm{~d}))$. Levels of CASP-9 were increased in GLSP+macrophage-treated H22 cells versus control cells $(P<0.01)$ (Figure $8(\mathrm{e}))$.

We continued to explore changes at the protein level. In Figures 8 (a) and 8 (c), the levels of PI3K were significantly decreased in GLSP+macrophage-treated H22 cells versus the control group $(P<0.01)$. Similarly, the levels of $\mathrm{p}$-AKT were significantly decreased in GLSP+macrophage-treated H22 cells $(P<0.01)$ (Figures $9(\mathrm{a})$ and $9(\mathrm{~d}))$. In Figure 8(e), the levels of AKT were not affected in GLSP+macrophage-treated $\mathrm{H} 22$ cells. We also measured the protein levels of BAX, BCL-2, and CASP-9 and found that the levels of proapoptotic BAX were markedly increased $(P<0.01)$ (Figures 9(b) and 9(f)), and the level of antiapoptotic BCL-2 was significantly decreased in GLSP+macrophage-treated $\mathrm{H} 22$ cells versus control groups $(P<0.01)$ 


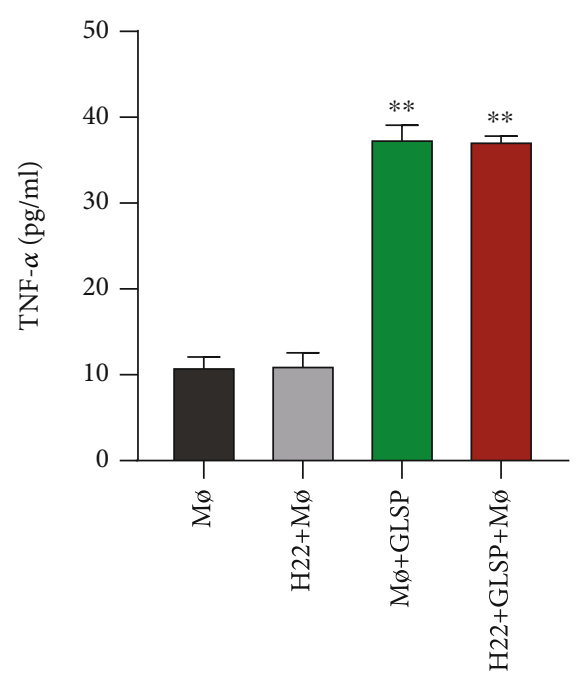

(a)

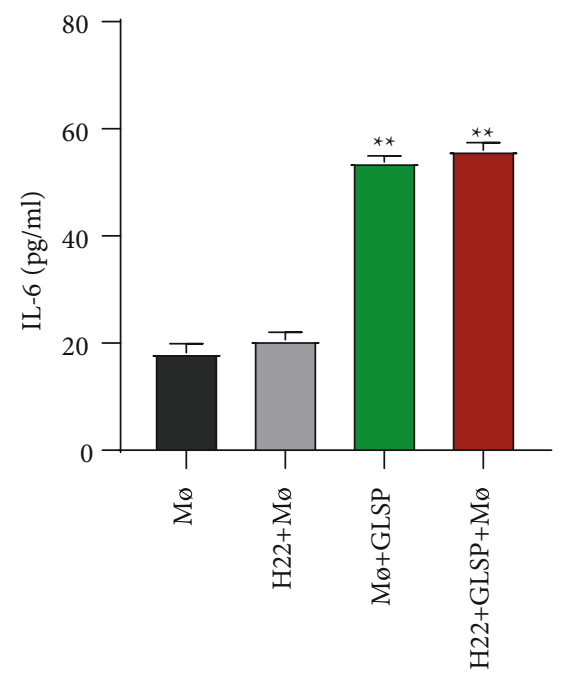

(c)

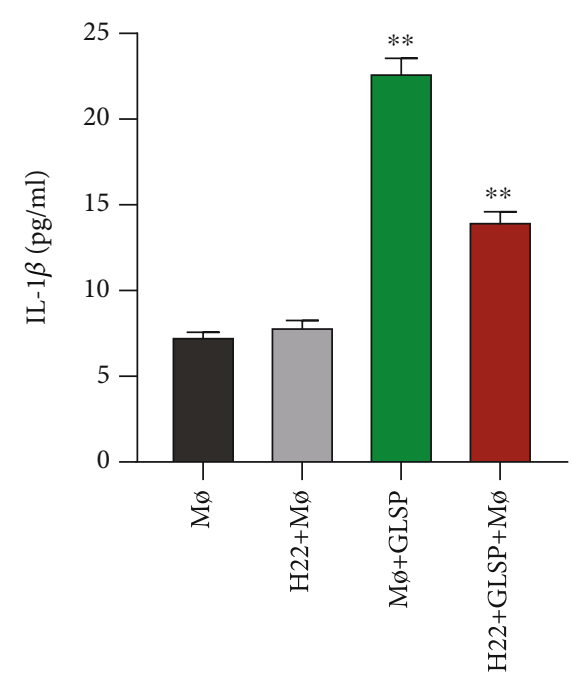

(b)

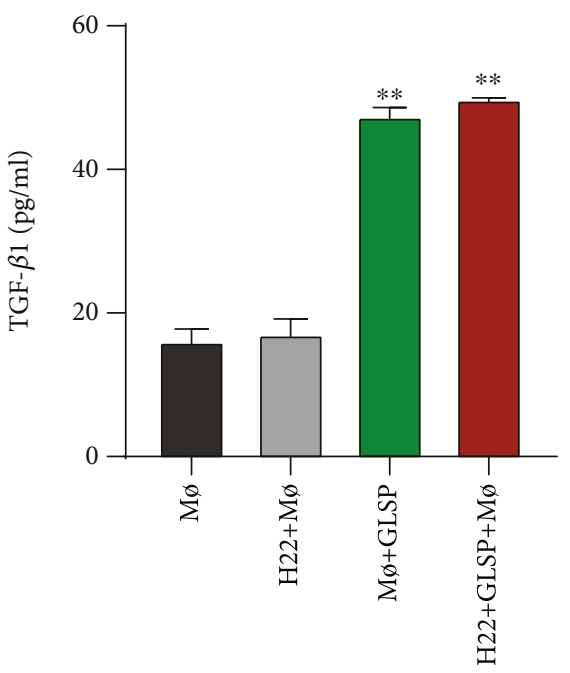

(d)

FIGURE 7: Increasing of proinflammatory cytokine expression by GLSP in macrophages. (a) TNF- $\alpha$ levels; (b) IL-1 $\beta$ levels; (c) IL-6 levels; (d) TGF- $\beta 1$ levels. Data is expressed as the mean $\pm \mathrm{SD}(n=5),{ }^{* *} P<0.01$ vs. the control group; ${ }^{\# \#} P<0.01$ vs. the H22+macrophage group. GLSP: Ganoderma lucidum spore polysaccharide.

(Figures 9(b) and 9(g)). Levels of CASP-9 were increased in GLSP+macrophage-treated $\mathrm{H} 22$ cells versus control cells $(P<0.01)$ (Figure $9(\mathrm{~h}))$. These results indicated that GLSP +macrophages could simultaneously activate genes and proteins in the mitochondria-mediated apoptotic signaling pathway.

\section{Discussion}

The primary characteristics of tumors are malignant proliferation and imbalance between cell proliferation and apoptosis [23]. Inhibiting proliferation and inducing apoptosis are excellent strategies for tumor treatment [24]. Previous research has shown that GLSP and G. lucidum triterpenes in G. lucidum spore powder can effectively inhibit tumors $[25,26]$. The antitumor mechanism of G. lucidum spore powder includes inhibition of tumor cell proliferation, induction of tumor cell apoptosis, and termination of the tumor cell cycle. Early experiments in our group had found that the water extract of G. lucidum spores showed no apparent inhibitory effect on tumor cells and no cytotoxicity change. However, after coculture with immune cells such as macrophages, it showed inhibition of tumor cell characteristics. In order to determine the mechanism of action of the antitumor effect of G. lucidum spores, we separately studied GLSP, G. lucidum spore triterpene, and G. lucidum spore oil. Finally, it was discovered that GLSP is the material basis for activating macrophages to enhance immunity and antitumor activity.

GLSP can activate the immune response. It improved the immune state to achieve the balance of the body's immune state and inhibit the development of tumors [27]. MTT results showed that GLSP alone did not affect the proliferation of $\mathrm{H} 22$ tumor cells, showing no cytotoxicity. Nevertheless, it inhibited $\mathrm{H} 22$ tumor cells by activating macrophages. In our cell cycle experiments, we found that the 


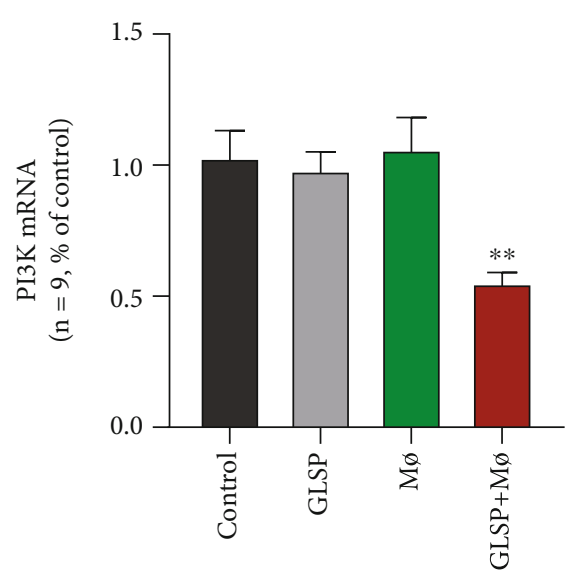

(a)

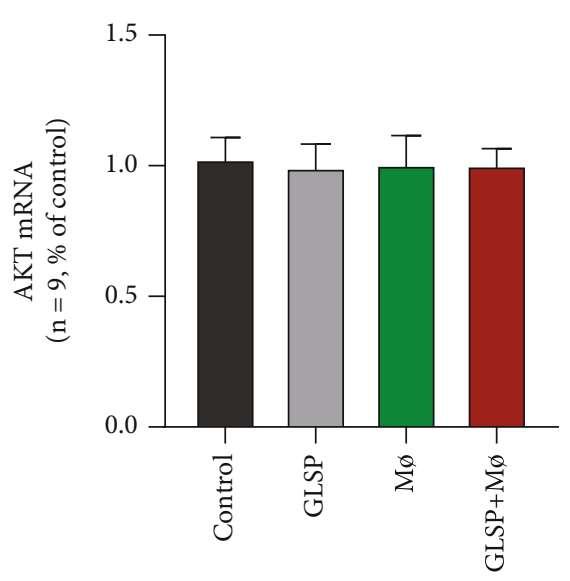

(b)

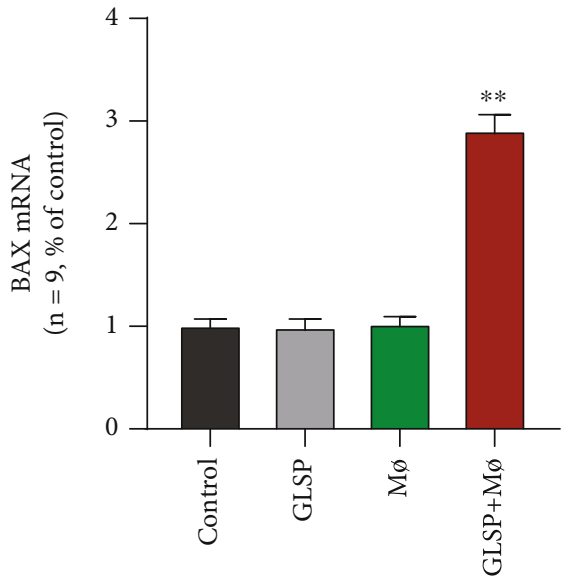

(c)

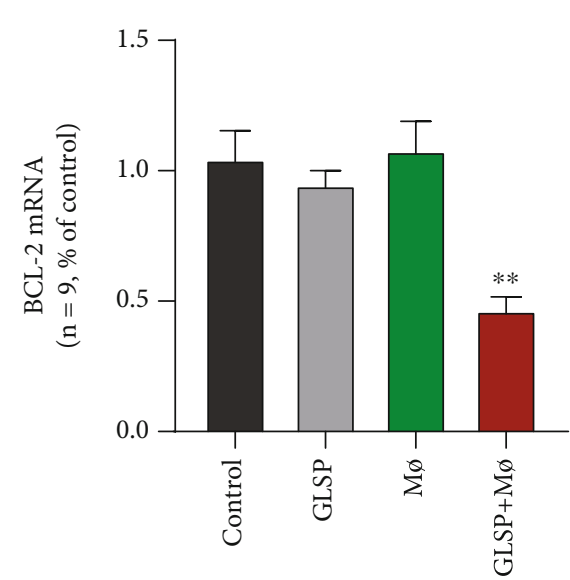

(d)

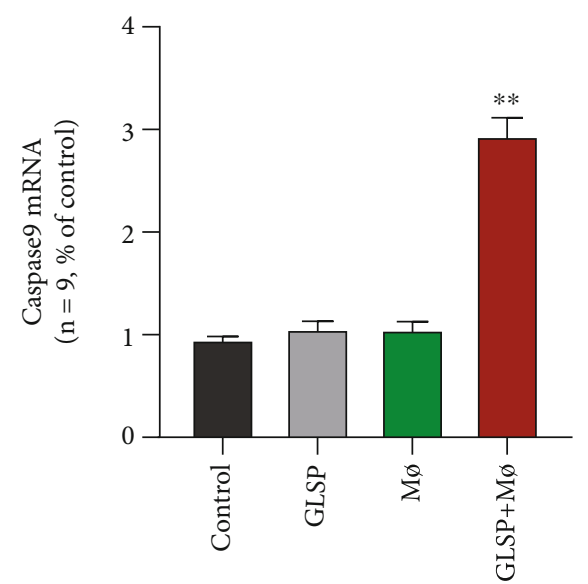

(e)

FIGURE 8: Effect of GLSP and Mø on the mRNA levels of PI3K/AKT and mitochondria-mediated apoptotic signaling pathway genes. H22 was treated with GLSP or Mø for $24 \mathrm{~h}$, and then, the (a) mRNA levels of PI3K, (b) AKT, (c) BAX, (d) BCL-2, and (e) CASP-9 were detected by qPCR. The histogram bars represent three independent experiments, and the values are the mean \pm SD. ${ }^{* *} P$ value $<0.01$ versus the control group. GLSP: Ganoderma lucidum spore polysaccharide.

macrophage supernatant containing GLSP can block tumor cells in the G2/M stage, whereas the macrophage supernatant alone had no blocking effect on H22 tumor cells. Cell cycle arrest at the G2/M phase shows that there is damage in the intracellular DNA, which is challenging to repair.

The mitochondrial apoptosis pathway is an integral part of the endogenous cell apoptosis regulation [28]. The endogenous pathway is activated by cellular stress, DNA damage, developmental signals, and loss of survival factors [29]. BCL-2 family proteins are composed of proapoptotic factors (BAX, Bad, Bak, and Noxa) and antiapoptotic factors (BCL-2, BCL-xL, BCL-w, and Mel-1) [30]. The BCL-2 family members are located on the mitochondria and can control its permeability, the release of cytochrome $C$, the activation of "priming" CASP-9, and the subsequent activation of "executive" CASP-3. Endogenous apoptosis can be inhibited through prosurvival signaling pathways such as PI3K/AKT and MAPK $[31,32]$. The PI3K/AKT pathway is an intracellular signaling pathway with phosphatidylinositol kinase and serine/threonine kinase activity. It is involved in regulating cell proliferation, apoptosis, sur- vival, growth, and other cellular physiological functions, and these processes are known to be affected in tumors [33]. The regulation of $\mathrm{PI} 3 \mathrm{~K} / \mathrm{AKT}$ activation is one of the hot topics in tumor pharmacology. As downstream molecules of PI3K/AKT, BCL-2 family proteins play a vital role in regulating apoptosis, mainly through endogenous pathways. Many survival factors can activate the PI3K pathway, leading to the activation of AKT, and AKT plays an essential role in cell survival signal transduction. PTEN has a negative regulatory effect on the PI3K/AKT pathway [34]. Activated AKT can phosphorylate and inhibit Bad, BAX, CASP9, GSK-3, and FOXO1 [32]. Western blot and RT-qPCR results showed that GLSP downregulated the expression of $\mathrm{PI} 3 \mathrm{~K}$ and $\mathrm{p}-\mathrm{AKT}$ genes and proteins in $\mathrm{H} 22$ cells. Our results showed a reduced phosphorylation level of AKT by inhibition of the PI3K/AKT signaling pathway, which simultaneously downregulates the expression of BCL-2 in $\mathrm{H} 22$ cells at mRNA and posttranslational levels and upregulates the expression of BAX, indicating that GLSP can inhibit the PI3K/AKT signaling pathway and induce apoptosis in liver cancer H22 cells (Figure 10). 


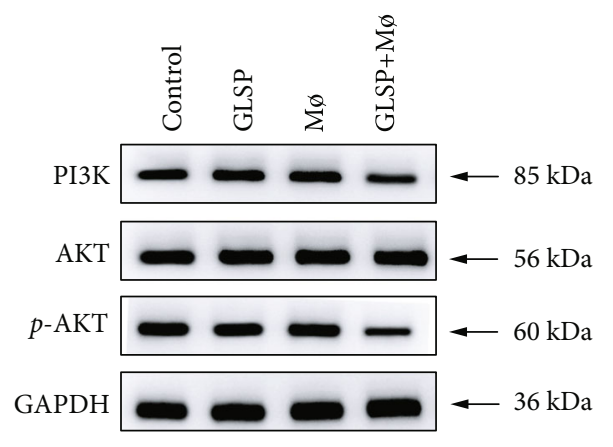

(a)

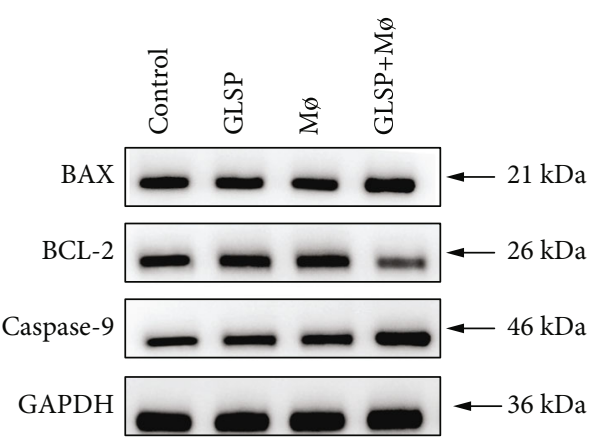

(b)

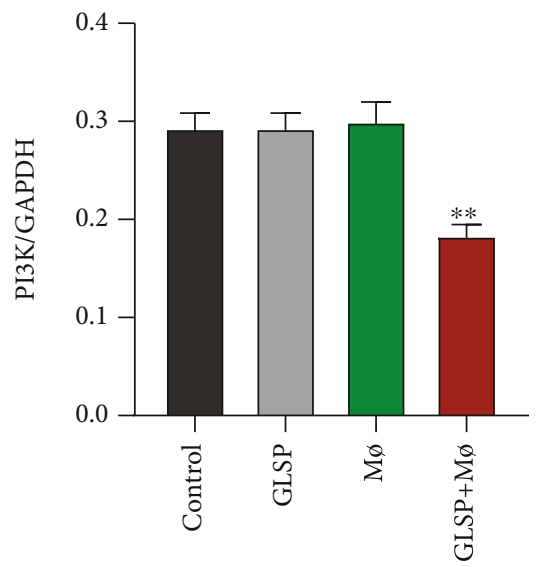

(c)

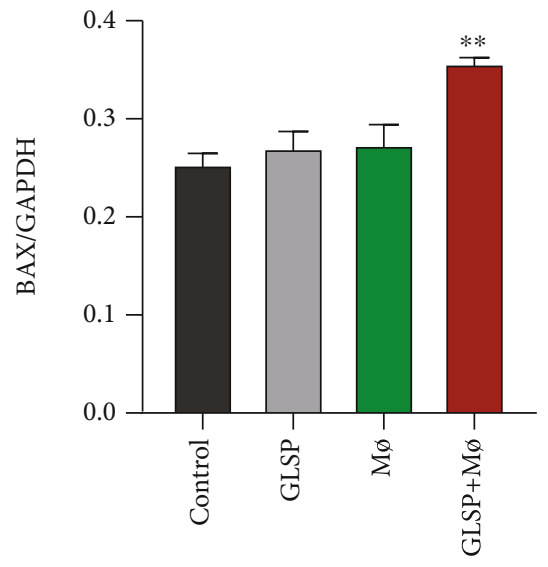

(f)

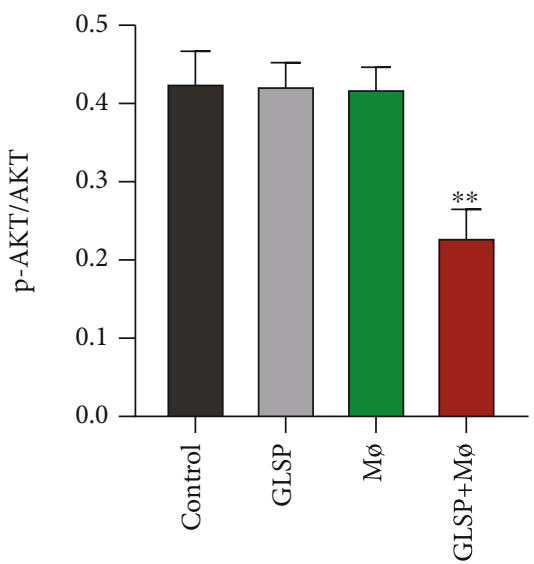

(d)

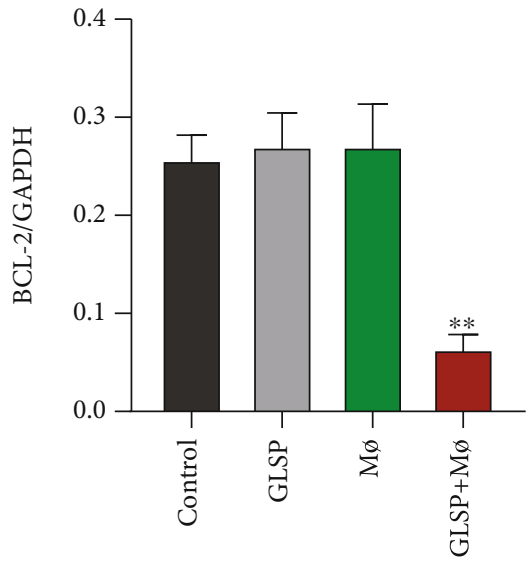

(g)

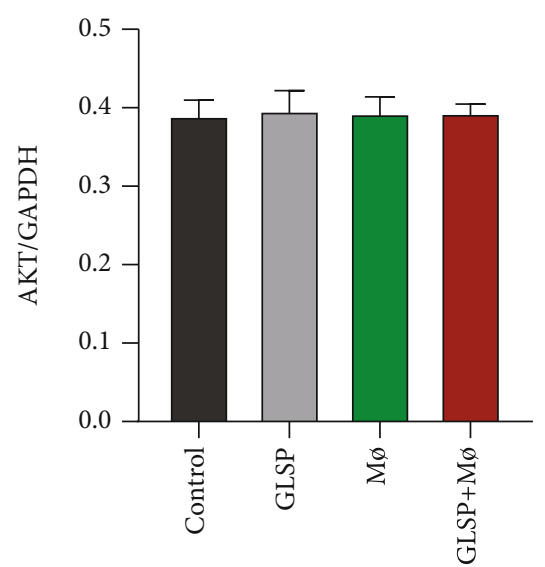

(e)

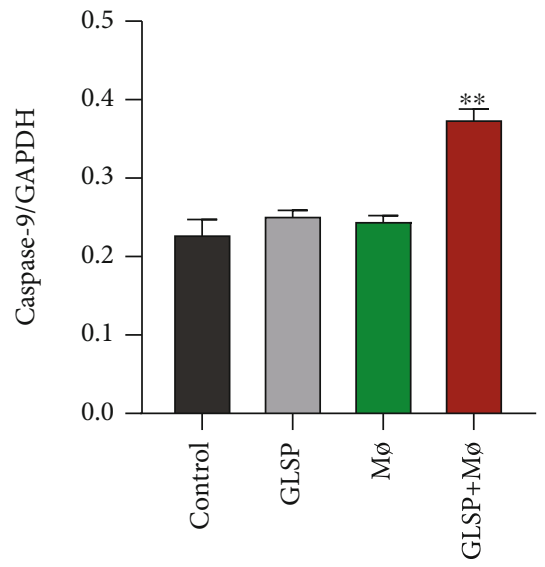

(h)

Figure 9: Effect of GLSP and Mø on the expression of PI3K/AKT and mitochondria-mediated apoptotic signaling pathway proteins. H22 cells were treated with GLSP or Mø for $24 \mathrm{~h}$, and then, the protein levels of PI3K, AKT, p-AKT, BAX, BCL-2, and CASP-9 were detected by WB. (a) Protein expression of PI3K/AKT signal pathway; (b) protein expression of BAX, BCL-2, and CASP-9; (c) relative PI3K/GAPDH protein; (d) relative p-AKT/AKT protein; (e) relative AKT/GAPDH protein; (f) relative BAX/GAPDH protein; (g) relative BCL-2/GAPDH protein; (h) relative caspase-9/GAPDH protein, and values are the mean \pm SD. ${ }^{* *} P$ value $<0.01$ vs. control group. GLSP: Ganoderma lucidum spore polysaccharide.

The monocyte-macrophage system is an essential part of innate immunity $[35,36]$. During inflammation or infection, monocytes in the blood are recruited into the tissue and differentiate into mature macrophages, a group of highly heterogeneous cells. Depending on the microenvironment, macrophages can polarize into different functional phenotypes [37]. According to their different activation states, they are mainly divided into classically activated macrophages (M1 type) and alternatively activated macrophages (M2 type) [38]. The polarization of phagocytic cells is affected by various cytokines in the microenvironment [39]. When the epithelial barrier is destroyed and pathogenic microorganisms invade, a large number of circulating monocytes are recruited under the action of chemokines and differentiate into 


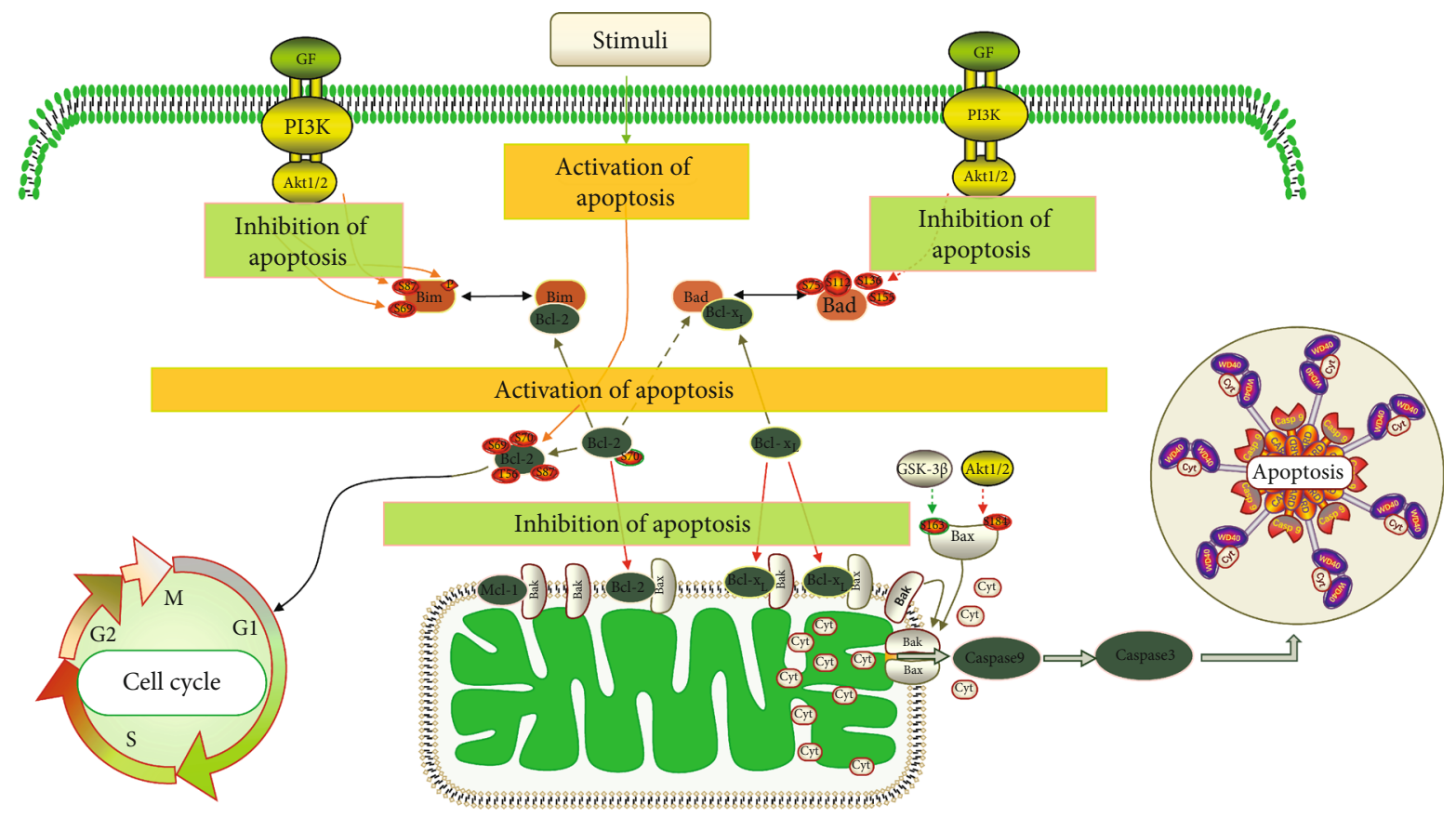

FIGURE 10: Schematic representation of the endogenous mitochondrial apoptosis pathway.

proinflammatory cells, namely, M1 macrophages, induced by local cytokines [40]. M1 macrophages have potent cytotoxicity; are highly sensitive to LPS; secrete many inflammatory factors and reactive oxygen products, such as IL-6, IL23, and TNF- $\alpha$; promote inflammation cascades and tissue damage; activate Th1/Th17 adaptive immunity; and promote the elimination of pathogenic microorganisms. M2 type macrophages also increase during the disease, inhibit the inflammatory response, avoid excessive damage to the tissue, and, at the same time, remove pathogenic bacteria and cell debris in the process of inflammation subsiding. They also promote tissue repair and immune balance. The immune balance of the intestine depends on the two types of macrophages working together and coordinating with each other. Therefore, regulating the balance between $\mathrm{M} 1$ and M2 macrophages is essential for the occurrence and development of cancer [41].

TAMs are derived from monocytes in the blood system and enter tumor tissues under the action of chemokines [42]. The colony-stimulating factor secreted by tumor cells can prolong the survival time of TAMs. When TAMs are moderately activated in the tumor environment (M1 type), they exert antitumor immune function, which can kill tumor cells and destroy vascular endothelium, thereby inhibiting tumor development. However, if this stimulus is not suppressed in a short time, TAMs will be polarized into M2 type under the action of various cytokines secreted by tumor cells, which is why most TAMs in tumor tissues are M2 type [38]. In contrast to the M1 type, M2 TAMs can secrete growth factors, angiogenesis factors, and proteases, thereby stimulating tumor cell proliferation, promoting angiogenesis and tumor cell invasion and migration, and escaping the surveillance of antitumor immunity [43]. Therefore, the induction of secondary polarization of TAMs in tumor tissues and the trans- formation of M2 TAMs to M1 have become an essential target for tumor therapy in recent years [44]. Previous research has found that glycopeptide derived from G. lucidum (Gl-PS) could promote polarization of M1 macrophage vs. M2 macrophages [45]. In our macrophage typing experiments, GLSP can increase the number of CD86+ cells, which is an M1 macrophage marker. When H22 tumor cells were cocultured with macrophages, we found that GLSP decreased the number of CD206+ macrophages, an M2 type marker. Overall, when $\mathrm{H} 22$ tumor cells are cocultured with macrophages in the TME, GLSP increases the ratio of M1/M2 macrophages. Therefore, we can speculate that GLSP has a regulatory effect on $\mathrm{M} 1$ and $\mathrm{M} 2$ macrophages in the tumor microenvironment.

Currently, chemotherapy is one of the most common cancer treatments, but it has noticeable side effects [46]. In contrast, "nutritional drugs" are known for their low toxicity. "Nutrition" is a concept that has attracted much attention to prevent and treat diseases [47]. Traditional Chinese medicine (TCM) is a rich source of nutritional medicine that has been used for thousands of years [48]. It has an excellent effect on treating many chronic diseases. Additionally, TCM can also be used as part of a daily diet. TCM is a safe and effective way to prevent and treat diseases. GLSP is one of the foremost effective ingredients in TCM as it has a wide range of therapeutic effects and relatively low toxicity. It is a promising nutritional drug and has attracted wide attention in biomedicine in recent years $[49,50]$. The above studies revealed that GLSP activates macrophages to induce apoptosis of $\mathrm{H} 22$ hepatocellular carcinoma cell in vitro and the biological mechanism. Next, we will continue to verify the biological activity of GLSP to enhance immunity and antitumor in vivo. 


\section{Conclusions}

In summary, GLSP reshapes the tumor microenvironment by activating macrophages, regulating the polarization of macrophages, and promoting the secretion of various inflammatory factors and cytokines. Moreover, we found that GLSP can block $\mathrm{H} 22$ tumor cells in the G2/M phase by activating macrophages and can activate PI3K/AKT signaling pathways to affect the mitochondrial apoptotic pathway and promote tumor cell apoptosis. Therefore, as a natural nutrient, GLSP can alter macrophage polarity and has potential to reshape the tumor microenvironment activity.

\section{Data Availability}

The data (original) used to support the findings of this study are available from the authors upon request.

\section{Conflicts of Interest}

The authors declare that they have no conflict of interests.

\section{Acknowledgments}

This work was supported by the National Key R\&D Program of China (2018YFC1706800).

\section{References}

[1] H. Jin, S. Wang, E. A. Zaal et al., “A powerful drug combination strategy targeting glutamine addiction for the treatment of human liver cancer," eLife, vol. 9, article e56749, 2020.

[2] H. Degroote, A. Van Dierendonck, A. Geerts, H. Van Vlierberghe, and L. Devisscher, "Preclinical and clinical therapeutic strategies affecting tumor-associated macrophages in hepatocellular carcinoma," Journal of Immunology Research, vol. 2018, Article ID 7819520, 9 pages, 2018.

[3] H. S. Lee and D. S. Oh, "Assessing the anti-cancer therapeutic mechanism of a herbal combination for breast cancer on system-level by a network pharmacological approach," Anticancer Research, vol. 40, no. 9, pp. 5097-5106, 2020.

[4] L. Han, X. Cao, Z. Chen et al., "Overcoming cisplatin resistance by targeting the MTDH-PTEN interaction in ovarian cancer with sera derived from rats exposed to Guizhi Fuling wan extract," BMC complementary medicine and therapies, vol. 20, no. 1, article 2825, 2020.

[5] B. B. Zhao, Z. H. Ye, X. Gao, and H. M. Li, "Diwu Yanggan modulates the Wnt/ $\beta$-catenin pathway and inhibits liver carcinogenesis signaling in 2-AAF/PH model rats," Current medical science, vol. 39, no. 6, pp. 913-919, 2019.

[6] M. F. Lau, K. H. Chua, V. Sabaratnam, and U. R. Kuppusamy, "In vitroandin silicoanticancer evaluation of a medicinal mushroom,Ganoderma neo-japonicumImazeki, against human colonic carcinoma cells," Biotechnology and Applied Biochemistry, pp. 1-16, 2020.

[7] G. Wang, J. Zhang, T. Mizuno et al., "Antitumor active polysaccharides from the Chinese MushroomSongshan lingzhi, the fruiting body ofGanoderma tsugae," Bioscience, Biotechnology, and Biochemistry, vol. 57, no. 6, pp. 894-900, 1993.

[8] D. Li, Q. Zhong, T. Liu, and J. Wang, "Cell growth stimulating effect of Ganoderma lucidum spores and their potential applica- tion for Chinese hamster ovary K1 cell cultivation," Bioprocess and Biosystems Engineering, vol. 39, no. 6, pp. 925-935, 2016.

[9] Z. Li, Y. Shi, X. Zhang et al., "Screening immunoactive compounds of Ganoderma lucidum spores by mass spectrometry molecular networking combined with in vivo zebrafish assays," Frontiers in Pharmacology, vol. 11, 2020.

[10] S. Tsutsumi, Y. Tokunaga, S. Shimizu et al., "Effects of indole and indoxyl on the intracellular oxidation level and phagocytic activity of differentiated HL-60 human macrophage cells," The Journal of Toxicological Sciences, vol. 45, no. 9, pp. 569-579, 2020.

[11] F. Graziano, E. Vicenzi, and G. Poli, "Plastic restriction of HIV-1 replication in human macrophages derived from M1/M2 polarized monocytes," Journal of Leukocyte Biology, vol. 100, no. 5, pp. 1147-1153, 2016.

[12] J. Zhou, A. Zhang, and L. Fan, "HSPA12B secreted by tumorassociated endothelial cells might induce M2 polarization of macrophages via activating PI3K/Akt/mTOR signaling," Oncotargets and Therapy, vol. 13, pp. 9103-9111, 2020.

[13] Y. le, W. Cao, L. Zhou et al., "Infection of Mycobacterium tuberculosis promotes both M1/M2 polarization and MMP production in cigarette smoke-exposed macrophages," Frontiers in Immunology, vol. 11, 2020.

[14] F. Zhang, Y. Xuan, J. Cui, X. Liu, Z. Shao, and B. Yu, "Nicorandil modulated macrophages activation and polarization via NF- $\kappa \mathrm{b}$ signaling pathway," Molecular Immunology, vol. 88, pp. 69-78, 2017.

[15] D. Ma, Y. Zhang, G. Chen, and J. Yan, "miR-148a affects polarization of THP-1-derived macrophages and reduces recruitment of tumor-associated macrophages via targeting $\operatorname{SIRP} \alpha$," Cancer Management and Research, vol. 12, pp. 8067-8077, 2020.

[16] J. Kozak, A. Forma, M. Czeczelewski et al., "Inhibition or reversal of the epithelial-mesenchymal transition in gastric cancer: pharmacological approaches," International journal of molecular sciences, vol. 22, no. 1, 2020.

[17] H. Lan, W. Zhang, K. Jin, Y. Liu, and Z. Wang, "Modulating barriers of tumor microenvironment through nanocarrier systems for improved cancer immunotherapy: a review of current status and future perspective," Drug Delivery, vol. 27, no. 1, pp. 1248-1262, 2020.

[18] Q. Meng, X. Luo, J. Chen et al., "Unmasking carcinomaassociated fibroblasts: key transformation player within the tumor microenvironment," Biochimica Et Biophysica Acta. Reviews on Cancer, vol. 1874, no. 2, article 188443, 2020.

[19] J. J. Eyre, R. L. Williams, and H. J. Levis, "A human retinal microvascular endothelial-pericyte co-culture model to study diabetic retinopathy in vitro," Experimental Eye Research, vol. 201, article 108293, 2020.

[20] C. H. Yeh, H. C. Chen, J. J. Yang, W. I. Chuang, and F. Sheu, "Polysaccharides PS-G and protein LZ-8 from Reishi (Ganoderma lucidum) exhibit diverse functions in regulating murine macrophages and T lymphocytes," Journal of Agricultural and Food Chemistry, vol. 58, no. 15, pp. 8535-8544, 2010.

[21] Y. Wang, Y. Liu, H. Yu et al., "Structural characterization and immuno-enhancing activity of a highly branched watersoluble $\beta$-glucan from the spores of_Ganoderma lucidum_," Carbohydrate Polymers, vol. 167, pp. 337-344, 2017.

[22] Y. Chen, J. Lv, K. Li et al., "Sporoderm-broken spores of Ganoderma lucidum inhibit the growth of lung cancer: involvement of the Akt/mTOR signaling pathway," Nutrition and Cancer, vol. 68 , no. 7, pp. 1151-1160, 2016. 
[23] L. Gao, H. J. Jin, D. Zhang, and Q. Lin, "Silencing circRNA_ 001937 may inhibit cutaneous squamous cell carcinoma proliferation and induce apoptosis by preventing the sponging of the miRNA-597-3p/FOSL2 pathway," International Journal of Molecular Medicine, vol. 46, no. 5, pp. 1653-1660, 2020.

[24] Y. Sun, Y. Liu, Y. Cai et al., "Downregulation of LINC00958 inhibits proliferation, invasion and migration, and promotes apoptosis of colorectal cancer cells by targeting miR-36195p," Oncology Reports, vol. 44, no. 4, pp. 1574-1582, 2020.

[25] S. Zhang, S. Nie, D. Huang, J. Huang, Y. Feng, and M. Xie, "Ganoderma atrum polysaccharide evokes antitumor activity via cAMP-PKA mediated apoptotic pathway and downregulation of $\mathrm{Ca}^{2+} / \mathrm{PKC}$ signal pathway," Food and Chemical Toxicology, vol. 68, pp. 239-246, 2014.

[26] S. Zhang, S. Nie, D. Huang, J. Huang, Y. Wang, and M. Xie, "Polysaccharide from Ganoderma atrum evokes antitumor activity via toll-like receptor 4-mediated NF- $\kappa \mathrm{B}$ and mitogenactivated protein kinase signaling pathways," Journal of Agricultural and Food Chemistry, vol. 61, no. 15, pp. 3676-3682, 2013.

[27] K. I. Lin, Y. Y. Kao, H. K. Kuo et al., "Reishi polysaccharides induce immunoglobulin production through the TLR4/TLR2mediated induction of transcription factor Blimp-1," The Journal of Biological Chemistry, vol. 281, no. 34, pp. 24111-24123, 2006.

[28] Y. Xu, J. Zheng, P. Sun et al., "Cepharanthine and curcumin inhibited mitochondrial apoptosis induced by PCV2," BMC Veterinary Research, vol. 16, no. 1, 2020.

[29] X. Wang, Q. Liu, D. Kong et al., "Down-regulation of SETD6 protects podocyte against high glucose and palmitic acidinduced apoptosis, and mitochondrial dysfunction via activating Nrf2-Keap1 signaling pathway in diabetic nephropathy," Journal of Molecular Histology, vol. 51, no. 5, pp. 549-558, 2020.

[30] C. D. Godwin, O. M. Bates, S. R. Jean et al., "Anti-apoptotic BCL-2 family proteins confer resistance to calicheamicinbased antibody-drug conjugate therapy of acute leukemia," Leukemia \& Lymphoma, vol. 61, no. 12, pp. 2990-2994, 2020.

[31] B. Dong, Z. Yang, Q. Ju et al., “Anticancer effects of Fufang Yiliu Yin formula on colorectal cancer through modulation of the PI3K/Akt pathway and BCL-2 family proteins," Frontiers in Cell and Development Biology, vol. 8, 2020.

[32] A. Robert, A. Pujals, L. Favre, J. Debernardi, and J. Wiels, “The BCL-2 family protein inhibitor ABT-737 as an additional tool for the treatment of EBV-associated post-transplant lymphoproliferative disorders," Molecular Oncology, vol. 14, no. 10, pp. 2520-2532, 2020.

[33] K. Ma, C. Zhang, and W. Li, "Gamabufotalin suppressed osteosarcoma stem cells through the TGF- $\beta /$ periostin/PI3K/AKT pathway," Chemico-Biological Interactions, vol. 331, article 109275, 2020.

[34] S. Zhang and R. Cui, "The targeted regulation of miR-26a on PTEN-PI3K/AKT signaling pathway in myocardial fibrosis after myocardial infarction," European Review for Medical and Pharmacological Sciences, vol. 24, no. 18, 2020.

[35] B. Al-Sarireh and O. Eremin, "Tumour-associated macrophages (TAMS): disordered function, immune suppression and progressive tumour growth," Journal of the Royal College of Surgeons of Edinburgh, vol. 45, no. 1, pp. 1-16, 2000.

[36] W. Yang, Y. Lu, Y. Xu et al., "Estrogen represses hepatocellular carcinoma (HCC) growth via inhibiting alternative activation of tumor-associated macrophages (TAMs)," The Journal of Biological Chemistry, vol. 287, no. 48, pp. 40140-40149, 2012.
[37] Z. Shen, H. Seppänen, S. Vainionpää et al., "IL10, IL11, IL18 are differently expressed in CD14 ${ }^{+}$TAMs and play different role in regulating the invasion of gastric cancer cells under hypoxia," Cytokine, vol. 59, no. 2, pp. 352-357, 2012.

[38] S. A. Almatroodi, C. F. McDonald, I. A. Darby, and D. S. Pouniotis, "Characterization of M1/M2 tumour-associated macrophages (TAMs) and Th1/Th2 cytokine profiles in patients with NSCLC," Cancer Microenvironment, vol. 9, no. 1, pp. 1-11, 2016.

[39] Y. Komohara and M. Takeya, "CAFs and TAMs: maestros of the tumour microenvironment," The Journal of Pathology, vol. 241, no. 3, pp. 313-315, 2017.

[40] S. Bi, W. Huang, S. Chen et al., "Cordyceps militaris polysaccharide converts immunosuppressive macrophages into M1like phenotype and activates T lymphocytes by inhibiting the PD-L1/PD-1 axis between TAMs and T lymphocytes," International Journal of Biological Macromolecules, vol. 150, pp. 261-280, 2020.

[41] M. Yin, J. Shen, S. Yu et al., "Tumor-associated macrophages (TAMs): a critical activator in ovarian cancer metastasis," Oncotargets and Therapy, vol. 12, pp. 8687-8699, 2019.

[42] Y. Li, F. Cao, M. Li et al., "Hydroxychloroquine induced lung cancer suppression by enhancing chemo-sensitization and promoting the transition of M2-TAMs to M1-like macrophages," Journal of Experimental \& Clinical Cancer Research, vol. 37, no. 1, 2018.

[43] D. F. Soave, M. P. Miguel, F. D. Tomé, L. B. de Menezes, P. R. Nagib, and M. R. Celes, "The fate of the tumor in the hands of microenvironment: role of TAMs and mTOR pathway," Mediators of Inflammation, vol. 2016, Article ID 8910520, 7 pages, 2016.

[44] X. Wang, X. Jiao, Y. Meng et al., "Methionine enkephalin (MENK) inhibits human gastric cancer through regulating tumor associated macrophages (TAMs) and PI3K/AKT/mTOR signaling pathway inside cancer cells," International Immunopharmacology, vol. 65, pp. 312-322, 2018.

[45] L. X. Sun, Z. B. Lin, J. Lu et al., "The improvement of M1 polarization in macrophages by glycopeptide derived from Ganoderma lucidum," Immunologic Research, vol. 65, no. 3, pp. 658-665, 2017.

[46] Q. Xu, Y. Yan, S. Gu et al., “A novel inflammation-based prognostic score: the fibrinogen/albumin ratio predicts prognoses of patients after curative resection for hepatocellular carcinoma," Journal of Immunology Research, vol. 2018, Article ID 4925498, 11 pages, 2018.

[47] D. J. Richards, "Nutritional products as drugs or food implications for development," Aging (Milano), vol. 5, 2 Supplement 1, pp. 59-64, 1993.

[48] S. Hua, Y. Zhang, J. Liu et al., "Ethnomedicine, phytochemistry and pharmacology ofSmilaxglabra: an important traditional Chinese medicine," The American Journal of Chinese Medicine, vol. 46, no. 2, pp. 261-297, 2018.

[49] S. D. Chen, M. C. Hsieh, M. T. Chiou, Y. S. Lai, and Y. H. Cheng, "Effects of fermentation products ofGanoderma lucidumon growth performance and immunocompetence in weanling pigs," Archives of Animal Nutrition, vol. 62, no. 1, pp. 22-32, 2008.

[50] S. W. Chiu, Z. M. Wang, T. M. Leung, and D. Moore, "Nutritional value of _Ganoderma_extract and assessment of its genotoxicity and anti-genotoxicity using comet assays of mouse lymphocytes," Food and chemical toxicology, vol. 38, no. 2-3, pp. 173-178, 2000. 